Boletín de la Sociedad Botánica de México 52: 3-29, 1992

DOI: $10.17129 /$ botsci.1403

Bol. Soc. Bot. México 52:3-29 (1992)

\title{
El género Ficus, subgénero Pharmacosycea (Moraceae) en Veracruz, México
}

\author{
GUillermo IBARRA-MANRÍQUEZ y THOMAS L. WENDT
}

\section{En memoria del maestro Efraín Hernández Xolocotzi}

\begin{abstract}
RESUMEN: Con base en estudios de material de herbario y en observaciones en el campo, se reconocen cinco especies de Ficus subgénero Pharmacosycea en Veracruz: Ficus insipida Willd., F. lapathifolia (Liebm.) Miq., F. maxima Mill., F. petenensis Lundell y F. yoponensis Desv. Se incluye clave de determinación, descripciones, sinonimia parcial, mapas de distribución e ilustraciones para cada especie.
\end{abstract}

ABSTRACT: Based on herbarium studies and field observations, five species of Ficus subgenus Pharmacosycea are recognized for Veracruz: Ficus insipida Willd., F. lapathifolia (Liebm.) Miq., F. maxima Mill., F. petenensis Lundell and F. yoponensis Desv. A key, descriptions, partial synonymy, distribution maps, and illustrations are provided.

El género Ficus (Moraceae), constituye uno de los elementos más conspicuos en las zonas tropicales del mundo, reconocible por su inflorescencia peculiar (el sicono o "higo"), exudado lechoso y sus estípulas amplexicaules (Berg, 1983; 1989; Burger, 1977; Corner, 1962, 1965, 1985; De Wolf, 1960; Hammel, 1986; Hill, 1967; Ramírez, 1977; Standley, 1917; Vázquez-Avila, 1981; Verkerke, 1989). Su distribución es pantropical y en el Nuevo Mundo se le localiza entre los $35^{\circ}$ latitud norte y los $35^{\circ}$ latitud sur, desde

1 Centro de Botánica, Colegio de Postgraduados, 56230, Chapingo, Edo. de México e Instituto de Biología, Universidad Nacional Autónoma de México, Apdo. Postal 70-233, Delegación Coyoacán, CP, 04510, México, D. F.

2 Centro de Botánica, Colegio de Postgraduados, 56230, Montecillo, México. Dirección actual: Department of Botany, Louisiana State University, Baton Rouge, Lousiana, 70803, USA. 
Florida hasta el norte de Argentina, siendo más abundante en elevaciones bajas o intermedias, menores de 2500 m (Berg, 1983; Burger, 1977; Ramírez, 1989). Su amplia distribución y el elevado número de interacciones que presenta con sus polinizadores y dispersores (Berg, 1990; Corner, 1985a; Ibarra-Manríquez, 1990, 1991; Janzen, 1979; Ramírez 1969, 1970, 1974; Wiebes, 1979, 1982, 1984, 1986, 1986a), lo perfilan como uno de los géneros más interesantes desde el punto de vista ecológico, evolutivo y sistemático. El entendimiento de estos aspectos contribuirá a dilucidar los patrones de estructura y dinámica de los ecosistemas de las regiones tropicales del mundo, permitiendo un aprovechamiento más adecuado de los valiosos recursos que éstos albergan.

Ficus es uno de los géneros arbóreos taxonómicamente más complejos de angiospermas y el número de sus especies se estima entre 700 y 800 (Berg, 1973, 1989, 1990). Corner (1962) propone para Ficus cuatro subgéneros (Ficus, Pharmacosycea, Sycomorus y Urostigma), con dos representantes en América: Pharmacosycea (Miquel) Miquel, sección Pharmacosycea y Urostigma Gasparrini sección Americana Miquel. En América, ambos taxa son monoicos, siendo más diverso el subgénero Urostigma con 100-120 especies en tanto que Pharmacosycea posee 20-30 taxa (Berg y Simonins, 1981; Berg, et al., 1984; Berg, 1990 y Corner, 1962, 1985).

\section{ANTECEDENTES}

La revisión taxonómica más completa y reciente sobre Ficus para México se encuentra en los trabajos de Standley $(1917,1922)$. En la primera referencia el autor proporciona una breve revisión de los trabajos taxonómicos sobre el género, entre los que destacan el de Liebmann (1851) y Hemsley (1883). Standley (1922) reconoce cinco especies para el subgénero Pharmacosycea en México, tres de las cuales están presentes en Veracruz: F. glalcescens (Liebm.) Miq., F. segoviae Miq., F. radula Humb. \& Bonpl. ex Willd. El autor sugiere la posibilidad de que $F$. glabrata H.B.K. se encuentre en Veracruz (Standley, 1917); además, otro nombre que maneja, F. mexicana (Miq.) Miq., está basado en un tipo colectado en el estado, aunque no lo mencione específicamente para él (De Wolf, 1965).

De Wolf $(1965,1967$; veáse también De Wolf, 1960) realiza un tratado del subgénero Pharmacosycea para América, empleando un concepto bastante amplio para la delimitación de las especies. Para México y Veracruz registra solamente dos taxa: $F$. maxima Mill., (incluyendo $F$. glaucescens, $F$. radula y $F$. mexicana, ésta última sensu Miquel, pero no Standley) y $F$. insipida Willd. (incluyendo $F$. segoviae y $F$. glabrata). Gómez-Pompa (1966), en su tratado para el género en la región de Misantla, Veracruz, sigue los conceptos de De Wolf, pero menciona además una tercera especie para el subgénero Pharmacosycea, F. lapathifolia (Liebm.) Miq., y hace notar los errores anteriores en la interpretación de este nombre.

Otros trabajos sobre Ficus son de utilidad para la determinación de las especies mexicanas (Standley, 1937; Standley y Steyermark, 1946; De Wolf, 1960; Burger, 1977; Croat. 1978; Vázquez-Avila, 1981; Hammel, 1986 y Carauta, 1989). Cabe destacar que 


\section{C. Berg (comunicación personal), está trabajando sobre el tratamiento del género en} el proyecto de Flora Neotropica.

Desafortunadamente, ninguna de las publicaciones señaladas con anterioridad proporciona un panorama adecuado para entender e identificar las especies del subgénero Pharmacosycea en Veracruz. Este estudio tiene como objetivos principales el delimitar taxonómicamente las especies del subgénero localizadas en el estado y aportar herramientas que faciliten su determinación.

\section{METOdologíA}

Para estudiar y diferenciar las especies de Ficus, subgénero Pharmacosycea en Veracruz, se utilizaron datos de: 1) la morfología general del adulto, con base en estudios de herbario y de campo, incluyendo una revisión detallada de la morfología de las flores y los frutos; 2) la ecología de las especies, basado en estudios de campo;3) la germinación y morfología de las plántulas, y 4) la morfología de los granos de polen. Los resultados de los puntos 3 y 4 pueden ser consultados en (Ibarra-Manríquez, 1990, 1992) y no cambian los resultados taxonómicos que aqui se presentan, los cuales se basan en los puntos 1 y 2 .

Es necesario mencionar que no se realizó un trabajo nomenclatural completo, ya que este requiere, entre otros aspectos: i) un conocimiento preciso de la variación de todas las especies incluidas en el subgénero Pharmacosycea, y ii) el acceso a el material tipo. El primer punto se encuentra fuera de los propósitos de este estudio y el segu:ıdo, es particularmente difícil, porque la mayoría de los tipos se encuentran en Herbarios europeos o están bajo la revisión del Dr. Berg. Por lo tanto, las decisiones nomenclaturales contenidas en este trabajo se basan en: 1) la revisión de las descripciones originales; 2) la revisión de los tipos, en su mayoría en la forma de microficha o fototipos, y 3) los trabajos de Burger (1977); De Wolf (1960, 1965, 1967); Gómez-Pompa (1966) y Standley (1917). En cuanto a la sinonimia, se incluye solamente: 1) basónimos; 2) los nombres mencionados en la sección de antecedentes y 3) los nombres basados en tipos colectados en Veracruz.

Se revisó material colectado en Veracruz del subgénero Phamacosycea contenido en los Herbarios CHAPA (Herbario Hortorio del Colegio de Postgraduados, Chapingo), ENCB (Herbario de Ciencias Biológicas del Instituto Politécnico Nacional), Museo Field de Chicago (F), LL (Universidad de Texas), MEXU (Herbario Nacional de la Universidad Nacional Autónoma de México), TEX (Universidad de Texas), US (Herbario Nacional de los Estados Unidos de América) y XAL (Herbario del Instituto Nacional de Investigaciones sobre Recursos Bióticos). Con la intención de tener una idea más apropiada sobre la variación de las especies fuera del estado, se estudió el material colectado en diferentes localidades de México y Centroamérica en los Herbarios mencionados, excepto para LL, TEX, y US. Sin embargo, las descripciones de las especies incluyen exclusivamente la variación que presentan las poblaciones veracruzanas. 
Se realizaron salidas de colecta a diferentes localidades de Veracruz, lo que permitió evaluar la variación intra e interespecífica. De cada ejemplar de colecta se fijaron (alcohol 70\%) siconos de diferentes tamaños, con objeto de realizar descripciones detalladas de sus estructuras internas. Para caracterizar mejor los diferentes tipos de flores y los frutos, se llevaron a cabo estudios con microscopio electrónico de barrido, los cuales no aportaron información adicional a la resultante de observaciones con el microscopio de luz (ver Ibarra-Manríquez, 1990); esta información se incluye en las descripciones de cada taxón.

Las medidas y caracterésticas contenidas en las descripciones de las especies fueron tomadas de material herborizado, excepto para la corteza, brecha, siconos, flores, frutos, exudado y lustre de la lámina de las hojas. Se incluyen las proporciones de las flores estaminadas, las flores pistiladas corto estiladas o "agalladas" (distinguidas por contener en el interior de su ovario una larva de avispa, con un orificio apical cuando éstas emergen), flores pistiladas "abortivas" y de manera indirecta, por medio del número de frutos, el porcentaje de las flores pistiladas con estilo largo o "semillíferas". Los frutos de las especies son las estructuras contenidas en el interior del sicono maduro (fase E, con base en el esquema propuesto por Galil y Eisikowitch, 1968; véase también IbarraManríquez, 1990, 1991), las cuales son consideradas frecuentemente como las "semillas" del higo.

En todas las estructuras se da primero su longitud, después su ancho y ocasionalmente el grosor se indica como una tercera medida. La estructura de las descripciones sigue de manera general el sugerido para la Flora de Veracruz (Gómez-Pompa y Nevling, 1970). No se incluyen todos los datos de localidad para el material de referencia estudiado, ya que esta información se publicará eventualmente en el tratado de la familia para la Flora de Veracuz, aunque por el momento, pueden ser consultados en IbarraManríquez (1990). Los ejemplares examinados se citan con base en el orden alfabético de los municipios y el colector; se proporciona el número de colecta y el (los) Herbario (s) donde se encuentra depositado el material. Los ejemplares de respaldo de Ibarra, sin referencia a ningún Herbario, es material que se encuentra en proceso de distribución a los siguientes Herbarios: CHAPA, ENCB, F, K, MEXU, MO, TEX, XAL y otros. Las siglas LT se refieren al Herbario de referencia de la Estación de Biología "Los Tuxtlas", considerado como una colección anexa de MEXU y que por lo tanto, carece de siglas reconocidas en el Index Herbariorum. La distribución de cada taxón se basa fundamentalmente en la consulta de ejemplares de Herbario y los mapas al respecto sólo ilustran la distribución en Veracruz.

\section{Clave de identificación para los subgéneros nativos de Ficus, en Veracruz}

1 Siconos solitarios en el nudo, verdes a amarillos, 3(-4) brácteas en la base, difíciles de observar a simple vista; flores estaminadas con (1-)2(-3) estambres, tecas con polen abundante, visible con lupa a manera de un polvo blanco o blanco amarillo; frutos con 
la superficie no pegajosa, crustácea; árboles de crecimiento autónomo, con contrafuertes definidos.

Pharmacosycea

1 Siconos pareados en el nudo, raramente solitarios, verdes a rojos o negros, 2 brácteas basales o una sola bilobulada, visibles a simple vista; flores estaminadas con 1 estambre, tecas con polen escaso, difícilmente visible, aun con lupa; frutos con una cubierta pegajosa, translúcida; árboles "estranguladores", hemi-epífitos o hemirupícolas, sin contrafuertes definidos

Urostigma

\section{Clave de determinación de las especies del subgénero Pharmacosycea, en Veracruz}

1 Pecíolo de la hoja madura cubierto por pequeñas escamas irregulares, de color café, caedizas al tacto (a veces no obvias en Ficus petenensis); yema terminal de 7-20 $(-56) \mathrm{mm}$ de largo; siconos con ostiolo aplanado o raramente sobre una columna apical, menor de $1 \mathrm{~mm}$ de largo.

2 Lámina de la hoja con ápice redondeado, agudo o anchamente corto apiculado, envés generalmente escabroso al tacto, (1.2-)1.4-2.6(-3) veces más larga que ancha, venas laterales principales en su parte central de $8-22(-33) \mathrm{mm}$ separadas entre sí; siconos pedunculados, de 9-30 mm de diámetro, esféricos u obpiriformes, pubescentes a glabrescentes y entonces aparentemente glabros, frecuentemente con pelos mayores de $0.1 \mathrm{~mm}$ de largo; flores y brácteas interflorales rosadas o rojizas en fresco................................................................ F. maxima

2 Lámina de la hoja con ápice caudado o acuminado, envés no escabroso al tacto, (2.2)2.4-4.1(-4.8) veces más larga que ancha, venas laterales principales en su parte central de (3-)5-11(-14) mm separadas entre sí; siconos sésiles, de 6-15 $\mathrm{mm}$ de diámetro, esféricos, finamente pubescentes, a veces con apariencia glabra, con pelos de hasta $0.1 \mathrm{~mm}$ de largo; flores y brácteas interflorales blancas en fresco.

F. petenensis

1 Pecíolo de la hoja madura liso, raramente algunos con pequeñas porciones estriadas, negras; yema terminal de (15-)22-110 mm de largo; siconos con ostiolo sobre una columna apical, mayor de $1 \mathrm{~mm}$ de largo.

3 Lámina de la hoja de (3.8-)8-22(-30) cm de ancho, base anchamente redondeada u obtusa, raramente cordada, ápice obtuso o agudo, raramente acuminado; yema terminal de (2-)4-5(-7) mm de grosor; brácteas del ostiolo mayores de $1 \mathrm{~mm}$ de largo, de color café al secar; brácteas basales del sicono generalmente persistentes, de 1-5 mm de largo. F. lapathifolia

3 Lámina de la hoja de (2-)3.5-9.5 cm de ancho, base ancha a estrechamente aguda, raramente obtusa, ápice acuminado o apiculado; yema terminal de 1-3 mm de grosor; brácteas del ostiolo menores de $1 \mathrm{~mm}$ de largo, negras al secar; brácteas basales del sicono generalmente pronto caedizas, de 0.6-2 $\mathrm{mm}$ de largo.

4 Siconos maduros de 2-3.8 cm o más de diámetro, esféricos u obpiriformes, ostiolo raramente sobre una columna apical, de hasta $2 \mathrm{~mm}$ de largo; flores y brácteas interflorales rosadas o rojizas en fresco; lámina de la hoja frecuentemente más ancha de su parte media hacia la base, usualmente con 
5-11 pares de venas laterales principales, considerando $8 \mathrm{~cm}$ de su base hacia el ápice (en hojas mayores de $10 \mathrm{~cm}$ de largo), vena submarginal ausente o visible, cuando presente regularmente con los arcos de las venas secundarias de 1-2.5 $\mathrm{mm}$ de largo; ripario, raramente en vegetación secundaria o selvas no riparias F. insipida

4 Siconos maduros de 1.3-1.9 $\mathrm{cm}$ de diámetro, esféricos, ostiolo sobre una columna apical, tubular, de 1-3 mm de largo; flores y brácteas interflorales blancas en fresco; lámina de la hoja más ancha en su parte media o por encima de ésta hacia el ápice, usualmente con 10-18 pares de venas laterales principales considerando $8 \mathrm{~cm}$ de su base hacia el ápice (en hojas mayores de $10 \mathrm{~cm}$ de largo), vena submarginal visible, generalmente con los arcos de las venas secundarias menores de $1 \mathrm{~mm}$ de largo; selvas y vegetación secundaria no riparia o en ocasiones riparia

F.yoponensis

\section{Tratamiento taxonómico}

Ficus subgénero Pharmacosycea (Miq.) Miq. (Ann. Mus. Bot. Lugduno-Batavum 3:299. 1868), sección Pharmacosycea. Lectotipo: F. maxima Mill., (véase De Wolf, 1965).

Arboles autónomos, contrafuertes presentes, corteza lisa, brecha de la corteza de 0.5-1 cm de grosor, blanca con bandas anaranjadas y exudado blanco, abundante; yema terminal verde, verde amarilla o café verdosa, glabra, lanceolada; hojas simples, alternas, base simétrica, el haz con tricomas cistolíticos visibles a manera de granos de azúcar o escamas, blancos o grises, opaco, lustroso en fresco, envés más pálido, venación pinnada, broquidódroma, venas intersecundarias compuestas, margen entero; pecíolo con exudado blanco al desprenderlo del tallo; estipulas dos, verde amarillas o amarillas, lanceoladas, margen ligeramente dentado, caducas, frecuentemente visibles en la yema terminal; siconos solitarios, verdes a amarillos, axilares a las hojas, pedúnculados o sésiles, 3(-4) brácteas basales, verdes o de color café, glabras; brácteas interflorales glabras; flores pistiladas polisépalas, sépalos glabros, translúcidos, costa evidente, con ápice agudo o redondeado, estaminodios ausentes, pistilo simple, blanco, ovario elipsoide o raramente obovoide, estilo lateral, simple o dividido; flores estaminadas gamopétalas, corola translúcida, tubular o subglobosa, glabra, 4- 5 lóbulos conduplicados, costa evidente, con ápice agudo o redondeado, estambres (1-)2-3, filamentos blancos, anteras café amarillas, divergentes, exertas, pistilodio blanco, localizado entre la base de los filamentos, estilo simple, raramente dividido; fruto elipsoide, raramente obpiriforme o globoso, café pálido, superficie crustácea, lisa, lustrosa, glabra, embrión curvo, blanco, glabro, cotiledones 2, 2/3 más largos que la radícula.

Ficus insipida Willd. Sp. Pl. 4:1143. 1806. Tipo: Venezuela, Caracas, Bredemeyer 32

(Holotipo: B, microficha IDC 7440.1399(I.2)!; Isotipo: P (fide De Wolf 1965, 1967). F. glabrata H.B.K., Nov. Gen. Sp. 2:47. 1817. Tipo: Colombia, cerca Bojorque y Teneriffe, río Magdalena. Humboldt \& Bonpland (Holotipo: P, microficha IDC 602?. 31(III.6)!.). 
F. segoviae Miq., Ann. Mus. Bot. Lugduno-Batavum 3:300. 1868 (Nomen novum para Pharmacosycea angustifolia Liebm.).

Pharmacosycea angistifolia Liebm., Kongel. Danske Vidensk. Selsk. Skr., ser. 5, Naturvidensk. Math. Afh. 2:333. 1851. (Non Ficus anglstifolia Roxb., 1832). Tipo: Nicaragua, prope Tantasmo in Segovia, 1/48 Oersted 14334 (Holotipo: C, microficha IDC 2204.146(II.4)!; Isotipo C, microficha IDC 2204.146(II.5)!..).

F. mexicana auct. non Miq.

Nombre común: Amate, Higuera, Higuera blanca, Higuera macho, Higuerilla, Japoí.

Arboles de (4-)12-35(-50) m; fuste 1(-5), $2-8 \mathrm{~m}$ de alto, rollizo, recto, 0.4-2.5 $\mathrm{m}$ de diámetro arriba de los contrafuertes; contrafuertes 4-8( -15 cuando existen varios fustes), 0.5-2.5 m de alto, rectos; corteza café grisácea o café pálida, lenticelas inconspicuas, de $1 \mathrm{~mm}$ de diámetro, negras o de color café; exudado blanco, escaso en la corteza pero abundante en madera y ramas juveniles, denso, urticante al contacto con la piel; copa densa, redondeada. Yema terminal (15-)30-65(-110) x 1.5-3 mm; entrenudos (3-)7-23 $(-35)$ x 2-4(-6) mm, ovalados, café obscuros, glabros, lenticelas disponiéndose anularmente cerca del nudo o no evidentes. Hojas de (7-)10-25(-30) x 4-10 cm, (2-)2.3-3.6(-4.3) veces más largas que anchas, elípticas, estrechamente elípticas, lanceoladas u ovadas, raramente obovadas, papiráceas a coriáceas, base ancha a estrechamente aguda, ápice acuminado, raramente cortamente apiculado, haz verde obscuro, verde amarillo o verde grisáceo, glabro, envés verde pálido o verde amarillento, glabro, vena submarginal ausente o visible, cuando presente regularmente con los arcos de las venas secundarias de 1-2.5 mm de largo, venas laterales principales de 13-19(-22) pares, café verdosas o verde amarillas, alternas a opuestas, el primer par divergente menos de $45^{\circ}$ con respecto a la costa, el resto de $45-80^{\circ}$, las centrales (par quinto al décimo) de (4-)6-19(-22) mm separadas entre sí, prominentes en ambas caras, raramente menos marcadas por el haz; pecíolo (12-)25-80(-135) x 1-3 mm, verdoso a café pálido, liso o raramente con algunas porciones estriadas, acanalado por el haz, glabro; estípulas 30-70 (-125) x 2-6 mm, verde amarillas, glabras. Sicono 0.8-3.8 x 1-3.5 cm, 2-3.8 x 2- $3.8 \mathrm{~cm}$ cuando maduro, esférico u obpiriforme, verde con manchas amarillentas circulares, amarillento al madurar en fresco, verdoso a café negruzco al secar, glabro o raramente finamente puberulento, liso, paredes de 1.5-2 mm de grosor, ostiolo aplanado, raramente sobre una columna apical, tubular, prominente, (0.2-)1-2 x 1.5-2 mm; flores ca. 1088-1956 por sicono, estaminadas ca. 200-472 (18.4-24.1\%) y pistiladas ca. 888-1484 (75.9-81.6\%), estas últimas produciendo ca. 316-904 (29-46.2\%) flores "agalladas", ca. 320-464 (16.4-42.5\%) abortivas y ca. 108-260 (9.9-13.3\%) frutos; brácteas interflorales 1-5.2 x 0.1-0.5(-0.8) mm, líneares, lanceoladas o estrechamente oblongas a ovadas, conduplicadas a aplanadas, rosa pálidas, translúcidas, ápice agudo; flores pistiladas con pedicelo de (0-)1-5(6.5) x (0) 0.5-1 mm, terete a aplanado, rosa pálido, más evidente en el ápice, sépalos 4-5(-6), (1.2-)2-4.5 x 0.2-0.5 mm, lineares, elípticos o lanceolados, conduplicados, algunas veces falcados, rosados, pistilo 1.3-6 mm de largo, ovario 1.1-1.9 x 0.5-0.8 x 0.5-0.7 mm, estilo 0.8-5 mm de largo; flores estaminadas con pedicelo de (2.3-)3.5-6.5 x 0.5-0.8 mm, terete a aplanado, rosado, cáliz rosado, tubo 1-1.5 x 0.8-1 mm, lóbulos 1-2 x 0.5-1 mm, elípticos, estambres 2(-3), filamentos 2-3 x 0.5-0.8 mm, aplanados o semiteretes, anteras 1.7-2.1 x 
0.5-1 x 0.5-0.6 mm, pistilodio 0.4-0.9 mm; frutos 1.5-2.7 x 1-1.8 x 0.8-1.1 mm, cotiledones 1-1.3 x $0.3 \times 0.2 \mathrm{~mm}$, radícula 0.6-0.7 x $0.2 \mathrm{~mm}$. Pedúnculo del sicono (2-)7-17 x 1.5-3 mm, rollizo, más ancho hacia ambos extremos o sólo hacia el ápice, café, liso a ligeramente estriado, glabro o raramente finamente puberulento, recurvado al madurar el sicono; brácteas basales 3(-4), 1-2 × 2-3 mm, deltoides, ápice agudo, redondeado o hendido, verdes en fresco, verde amarillas, de color café o negras al secar, prontamente caducas. (fig. 1).

Tipos de vegetación y altitud. Riparia, incluso en pequeños riachuelos en pastizales, raramente mencionado como componente de la selva alta perennifolia. Esta especie

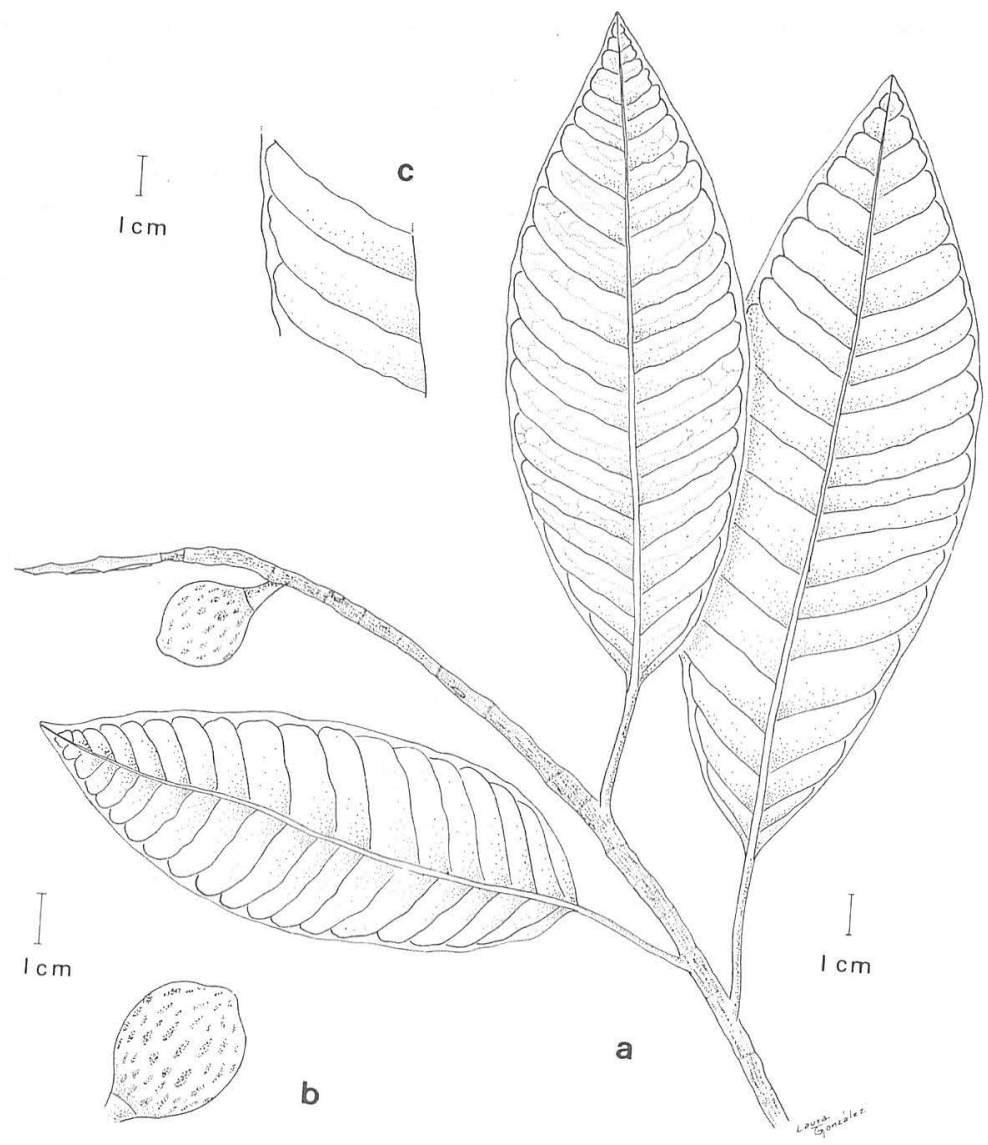

Fig.1. Ficus insipida Willd. A) Rama con hojas y siconos (Boege 3186), B) detalle del sicono (Boege 3186). 
parece estar restringida a la presencia de cuerpos de agua, aunque ocasionalmente es posible su desarrollo como un árbol ruderal; 0-500 (-900) $\mathrm{m}$ snm.

Fenología. Floración y fructificación durante todo el año. Wiebes (1986) indica que es polinizada por Tetrapus costaricantus Grandi (Agaonidae) en México y Panamá.

Distribución geográfica. México (por la vertiente del Pacífico desde Chihuahua hasta Chiapas y por el Golfo en Veracruz) hasta Brasil y Bolivia; la distribución en Veracruz se ilustra en la figura $2 \mathrm{~A}$.

Usos. Sombra y alimento (sicono) para ganado en pastizales. Fruto usado como carnada para pescar tortugas. La madera se usa para la elaboración de triplay. El exudado es útil para matar y curarse de parásitos en la piel.

Ejemplares examinados. Mun. Actopan, Novelo 431 (XAL), Ventura 3190 (ENCB); Mun. Alto Lucero, Cházaro y Oliva 2767 (XAL), Ventura 5174 (ENCB, LL); Mun. Catemaco, Beaman 5175 (F, MEXU), Boege 3186, 3187 (MEXU), Ibarra 42 (LT, MEXU), 3256, 3258, 3309, Miranda 8309 (MEXU), Sousa y Peña 7 (MEXU); Sousa 1380, 2551 (MEXU), 3291 (F, MEXU); Mun. Coatzintla, Córtes 480 (MEXU); Chavelas y Zamora ES-4988 (LL, MEXU); Mun. Colipa, Castillo y Córtez 1610 (XAL); Mun. Coxquihui, Mendoza y Evangelista 49 (MEXU); Mun. Dos Ríos, Ventura 11562 (CHAPA, XAL); Mun. Emiliano Zapata, Cházaro y Oliva 2320 (XAL); Mun. Hidalgotitlán, Brigada Dorantes 4043 (XAL), Brigada Vázquez 361, 483 (F, XAL), 619 (MEXU, XAL), 1608 (XAL), Ponce 252 (XAL), Valdivia 49, 319, 1944 (XAL); Vázquez 12 (MEXU); Mun. Jalcomulco, Nee y Castillo 22449 (F, TEX, XAL), Robles 115 (XAL); Mun. Jésus Carranza, Ibarra et al. 3259, Márquez 279 (XAL), Nevling y Gómez-Pompa 2571 (F, MEXU); Mun. Martínez de la Torre, Gómez-Pompa 8, 66, 1168 (MEXU), González y Garza 8394 (MEXU); Mun. Medellín, Ibarra y González 3244; Mun. Mecayapan, Nee y Tayl or 26512 (F); Mun. Minatitlán, Ibarra et al. 3263, 3264, Wendt et al. 2576 (CHAPA, ENCB, LL, XAL); 3525 (CHAPA); Mun. Misantla, Calzada 4108 (F, XAL), 4426 (XAL); Mun. Ozuluama, Avendaño et al. 664 (XAL); Mun. Papantla, Nee y Diggs 24649 (F, TEX, XAL); Mun. Puente Nacional, Calzada 5291 (F, XAL); Herrera et al. s.n. (MEXU, No. 170138); Mun. San Andrés Tuxtla, Cedillo 3288 (MEXU), Gentry et al. 32627 (LL), Ibarra 3009 (LT, MEXU), 3301, Ibarra et al. 3310, Lot 2243 (MEXU), Welbster y Armbruster 20950 (MEXU); Mun. Santiago Tuxtla, Nee y Taylor 26445 (F), Thomas y Villaseñor 3691 (MEXU); Mun. Tlapacoyan, Ventura 715 (ENCB); Mun. Veracruz, Gutiérrez 974, (XAL), 1075 (ENCB, MEXU, XAL), 1119 (CHAPA, ENCB, XAL); Mun. Desconocido, Ahshapanek 673 (TEX); Ramírez s.n. (MEXU, No. 49517, 49518), s.n. (MEXU, No. 10688), s.n. (MEXU, No. 11955), s.n. (MEXU, No. 111957).

Comentarios taxonómicos. Se trata de una de las especies más confundidas en material de herbario, trabajos florísticos y taxonómicos, puesto que se desconoce su variación a lo largo de toda su área de distribución. Las poblaciones localizadas en Veracruz no presentan problemas para su delimitación cuando presentan estructuras reproductivas, pues se caracterizan por sus siconos grandes, rosados o rojizos en su interior en fresco. En estado vegetativo puede confundirse con $F$. yoponensis, pero las características vegetativas mencionadas en la clave, permiten diferenciar ambos taxa en la mayoría del material revisado. 
Para otras localidades de México, la situación taxonómica de la especie no es tan clara. Especialmente en la vertiente del Pacífico, existen poblaciones que podrían representar otro taxón. Incluidas dentro de este problema se encuentran plantas tratadas por Standley $(1917,1922)$ como F. radulina S. Wats. y F. mexicana (Miq.) Miq. Cabe destacar que Standley (1917) cita a F. mexicana como una especie estranguladora, situación que no se ha observado en ninguno de los miembros de Phamacosycea presentes en México.

Un problema taxonómico adicional, es la existencia de material de herbario con características que sugieren la posibilidad de eventos de hibridación entre $F$. insipida y F. maxima [Veracruz, México, Miranda 4828 (MEXU); Guatemala, Standley 84601 (F); Costa Rica, Burger y Ramírez 4119 (F), Jiménez 93 (F); Panamá, Croat 12695 (F), Muenscher 12291 (F)]. Esta situación ha sido comprobada por Ramírez (1986), por medio de experimentos de cruzamiento, aunque si se considera la gran cantidad de material de herbario que existe de ambas especies y el número de colectas que presentan esta problemática, puede sugerirse que no se trata de un fenómeno muy frecuente. Adicionalmente, la presencia de diferentes polinizadores y nuestras observaciones de campo, confirman esta suposición.

En este trabajo no se reconocen las subespecies propuestas por Berg et al. (1984) para F. insipida, pues las diferencias entre las dos entidades no parecen ser concluyentes. Ficus lapathifolia (Liebm.) Miq., Ann. Mus. Bot. Lugduno-Batavum 3:297. 1868.

Urostigma lapathifolitm Liebm. Kongel. Danske Vidensk. Selsk. Skr., ser. 5, Naturvidensk. Math. Afh. 2:319. 1851. Tipo: Liebmann 14320, Yecoatla [= Yecuatla], Veracruz. (Sintipo (?): C (Fototipo F!). [La descripción original también cita la especie en Colipa, Veracruz, pero no queda claro si existe una muestra de dicha localidad].

Nombre común: Amate, Amate de caballo, Amate de hoja ancha, Higuera, Higo durazno.

Arboles de 7-40 m; contrafuertes 5-10, 0.3-3(-4) m de alto, rectos, raramente sigmoides; fuste $1(-3)$, de $3-15 \mathrm{~m}$ de alto, rollizo a ligeramente acostillado, recto, (0.2-)0.4-1 m de diámetro arriba de los contrafuertes; corteza café grisácea, café pálida o verde grisácea, lenticelas inconspicuas, de $1 \mathrm{~mm}$ de diámetro, negras o de color café; exudado blanco, después de $12 \mathrm{hrs}$. café pálido, escaso en la corteza pero abundante en madera y ramas juveniles, diluido, urticante al contacto con la piel; copa abierta o densa, redondeada. Yema terminal 35-85(-105) x (2-)4-5(-7) mm; entrenudos 6-20(-45) x 4-10 $\mathrm{mm}$, ovalados, café negruzcos, raramente café verdosos, lisos, ocasionalmente escamosos o ligeramente estriados en alguna de sus partes, pubescentes, glabrescentes, con tricomas de 0.5-1 mm de largo, lenticelas con arreglo anular cerca del nudo o no evidentes. Hojas (7-)14.7-36 cm (-50 cm en individuos juveniles) x (3.8-) $8-22 \mathrm{~cm}(-30 \mathrm{~cm}$ en individuos juveniles), (1.4-)1.6-2(-2.6) veces más largas que anchas, elípticas, ovadas, raramente obovadas u ampliamente obovadas, coriáceas, base anchamente redondeada, obtusa o raramente caudada, ápice obtuso o agudo o raramente apiculado, haz verde grisáceo, verde negruzco o verdoso con tonos de color café, ligeramente escabroso al tacto, raramente aterciopelado, sobre todo cuando se trata de hojas jóvenes, glabrescente, con tricomas escasos, envés verde café o café amarillento, pubescente, glabres- 


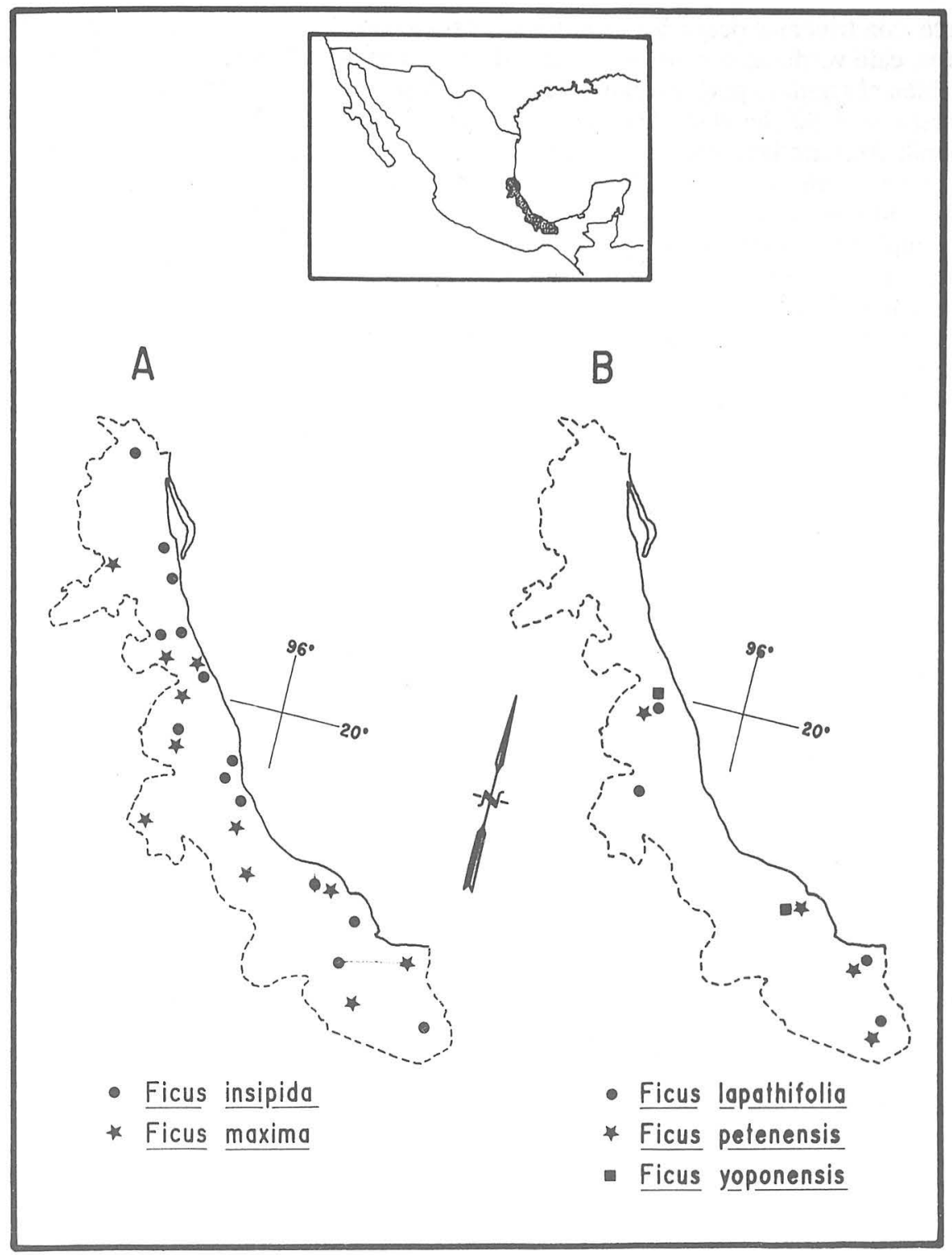

Fig.2. Distribución geográfica de las especies de Ficus, subgénero Pharmacosycea presentes en Veracruz. 
cente, con tricomas pequeños, ligeramente escabroso al tacto, venas laterales de 12-18 pares, café verdosas o verde amarillas, alternas a opuestas, el primer par (raramente también el segundo par) divergente de $45-50$ o (raro de 50-80 $)$ con respecto a la costa, el resto de $50-80^{\circ}$, las centrales (par quinto al décimo) de $12-32 \mathrm{~mm}$ ( $-42 \mathrm{~mm}$ en plantas juveniles) separadas entre sí, más prominentes por el envés; pecíolo (15-)30-75 mm (-135 $\mathrm{mm}$ en individuos juveniles) × $2-4 \mathrm{~mm}(-6 \mathrm{~mm})$, café verdoso o verde grisáceo, liso, aplanado por el haz en fresco y al secarse con (1-)2-7 canales que lo recorren longitudinalmente, glabrescente, con escasos tricomas hacia su base; estípulas 5-110 x 5-11 mm, glabras. Sicono 1-2.5 x (0.9- ) 1.3-2.6 cm, 2-2.6 x 2-2.6 cm cuando maduro, esférico, raramente elipsoide u obpiriforme, verde con manchas amarillentas circulares en fresco, amarillo al madurar, negro al secar, con las manchas más obscuras, evidentes, gris pubescente, con excepción de las manchas que son glabras, ligeramente escabroso al tacto o excepcionalmente liso, paredes 0.8-2 $\mathrm{mm}$ de grosor, ostíolo sobre una columna apical (0.5-)1-3 x 2-4 mm, brácteas 3-5 × 3-5 mm, verdes o de color café, frecuentemente alguna de ellas erecta; flores ca. $612-2324$ por sicono, estaminadas ca. $72-604$ (11.8-26\%) y pistiladas ca. 540-1720 (74-88.2\%), estas últimas produciendo ca. 348-488 (21-56.9\%) flores "agalladas", ca. 84- 1040 (13.7-44.7\%) abortivas y ca. 108-192 (8.3-17.6\%) frutos; brácteas interflorales (1-)3.2-7.2 x (0.1-)0.4-1 mm, líneares o lanceoladas, conduplicadas, blancas, translúcidas, ápice agudo, raramente redondeado; flores pistiladas con pedicelo de (0-)1.2-5 x (0-)0.4-0.8 mm, terete a aplanado, blanco, sépalos 5-6(-8), (1.8-)2-4 x 0.2-0.6(-0.8) mm, lineares, elípticos, lanceolados o estrechamente oblongos a ovados, conduplicados, algunas veces falcados, translúcidos, pistilo $1.5-5 \mathrm{~mm}$ de largo, ovario 1-1.5 $\times 0.8-1 \times 0.5-0.6 \mathrm{~mm}$, estilo $0.8-5 \mathrm{~mm}$ de largo; flores estaminadas con pedicelo de (2-)4.5-7 x 0.4-1.5 mm, terete a aplanado, blanco, cáliz blanco, tubo 1-1.5 x 1-1.5 mm, lóbulos 4-5, 1-2 x 0.5-1.2 mm, elípticos, estambres (1-)2, filamentos 1.5-2.5 x 0.3-0.7 mm, aplanados o semiteretes, anteras 1.5-2 x 0.6-1 x 0.3-0.6 mm, pistilodio 0.4-0.8 mm; frutos 2-2.8 $\times 1-1.8 \times 0.7-1 \mathrm{~mm}$, cotiledones $1.1 \times 0.8 \times 0.2 \mathrm{~mm}$, radícula $0.5 \times 0.2 \mathrm{~mm}$. Pedúnculo del sicono (0-)2-10 x 1.5-4 mm (siconos generalmente sésiles cuando inician su desarrollo), rollizo o más ancho hacia ambos extremos, verde grisáceo o café negruzco, liso a ligeramente estriado, pubescente, recurvado al madurar el sicono; brácteas basales $3(-4), 1-3.5(-5) \times(1-) 3.5-9 \mathrm{~mm}$, deltoides, ápice agudo, redondeado o hendido, verdes en fresco, café amarillas o negras al secar, glabras, no prontamente caducas, en ocasiones localizándose en la parte media del sicono o incluso cerca del ostíolo. (fig. 3).

Tipos de vegetación y altitud. Selva alta perennifolia, selva mediana subperennifolia o subcaducifolia, vegetación secundaria derivada de estos tipos de vegetación, riparia, pastizales o ruderal; 30-800 (-1800) m snm.

Fenología. Floración y fructificación durante todo el año.

Distribución geográfica. Confinada a nuestro país, en Veracruz, Tabasco, Oaxaca y Chiapas; la distribución en Veracruz se ilustra en la figura 2B.

Usos. Sombra y alimento (sicono) para ganado en pastizales. La madera se usa para chapa (triplay). Los contrafuertes se utilizan para construir vasijas.

Ejemplares examinados. Mun. Hidalgotitlán, Brigada Dorantes 2601 (F, MEXU, XAL), 3113 (ENCB, XAL), Brigada Vázquez 1001 (ENCB, MEXU), 1646 (ENCB, XAL), Nee 30020 (XAL), Ponce 219 (F, XAL), Valdivia 818 (XAL), Wendt et al. 2743 


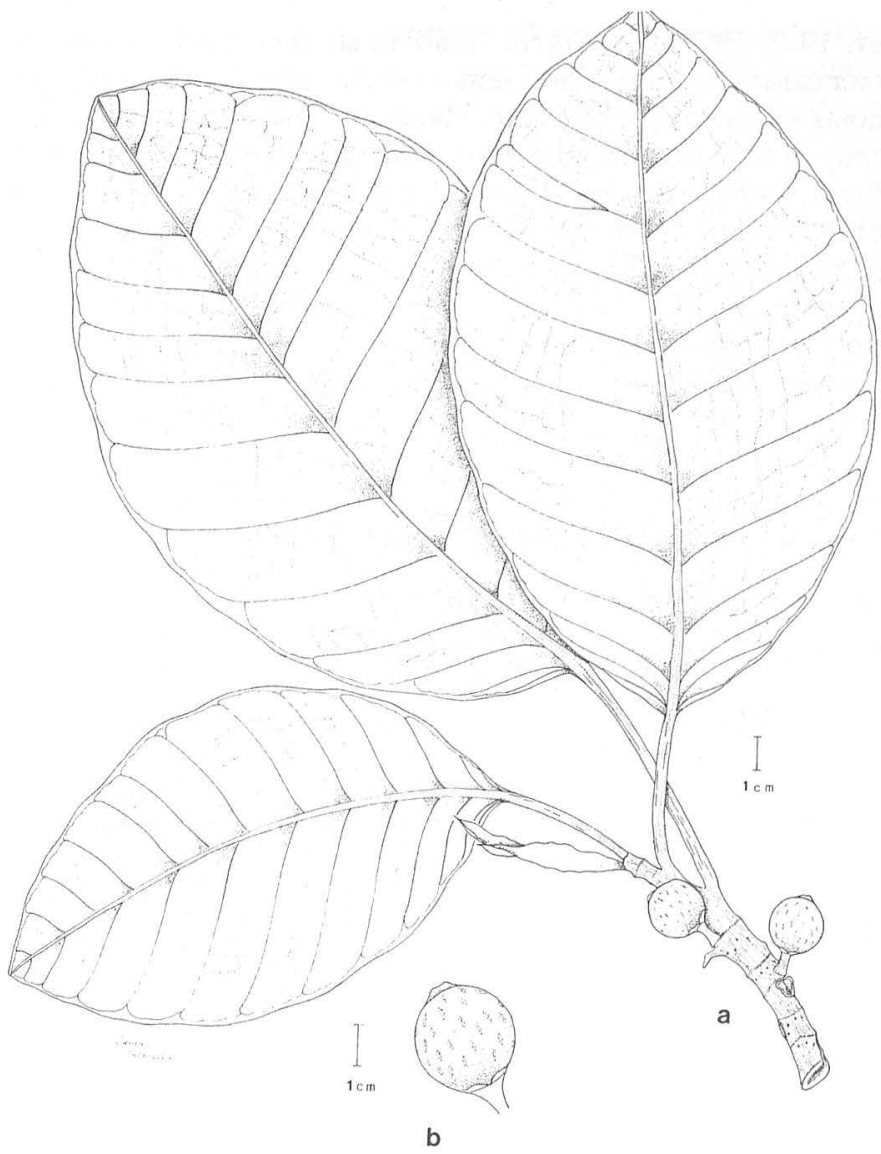

Fig.3. Ficus lapathifolia (Liebm.) Miq. A) Rama con hojas y siconos (Wendt et al. 2743), B) detalle del sicono (Castillo et al. 1693).

(CHAPA), Williams 8443 (F), 8772 (F), 8781 (F); Mun. Huatusco, Avendaño y Vázquez 749 (XAL); Mun. Jésus Carranza, Márquez 239 (XAL), Vázquez-T. et al. 2655 (CHAPA); Mun. Juchique de Ferrer, Castillo et al. 1693 (F, XAL), Cházaro 1703 (F, XAL), Gómez-Pompa y Riba 301 (MEXU), Ibarra y Sinaca 3215, 3218, 3227, Ibarra et al. 3219, 3236, Ibarra y Carmona 3241; Mun. Minatitlán, Ibarra et al. 3261, 3262, 3265, 3266, 3267, 3268; Mun. Misantla, Gómez-Pompa y Riba s.n. (MEXU, No. 92775$), 946$ (F, US); Martínez 63 (MEXU), s.n. (ENCB).

Comentarios taxonómicos. Standley $(1917,1946)$ utilizó incorrectamente este binomio para determinar y describir los ejemplares de herbario de una especie del subgénero Urostigma (Gómez-Pompa, 1966), denominada actualmente F. morazaniana 
Burger (Burger, 1973, 1977). Este error también se encuentra en Condit (1969). La especie puede ser caracterizada sin problemas en Veracruz, básicamente por las dimensiones de sus hojas y el sicono pubescente, blanco en su interior en fresco.

Gómez-Pompa (1966) sugiere que F. lapathifolia y F. tonduzii Standley (Honduras a Ecuador; Burger, 1977) son taxa similares, que podrían ser tratados como una sola especie. Burger (1977) apoya este argumento, incluyendo dentro de esta problemática a F. macbridei Standley (Nicaragua a Perú y Venezuela; Burger, 1977; C. Todzia, comunicación personal). Otro taxón que claramente se asocia a este grupo es $F$. guajavoides Lundell (Belice y Guatemala). En todos estos taxa, la epidermis del pecíolo es exfoliante, desprendiéndose en escamas pequeñas, a diferencia de $F$. lapathifolia, cuyo pecíolo tiene la superficie lisa. Ficus tonduzii y $F$. guajavoides difieren además por la presencia de una vena submarginal prominente y siconos sésiles ( $F$. tonduzii) o sobre pedúnculos largos, de 18-35 mm de largo (F.guajavoides). La especie más emparentada con $F$. lapathifolia es $F$. macbridei, que difiere además de lo mencionado para el pecíolo, en poseer una pubescencia más densa en el envés de la hoja.

Ficus maxima Miller, Gard. Dict. ed. 8 (Ficus No. 6). 1768.

Lectotipo (De Wolf, 1960): Sloane, Voy. Jamaica, 2: t. 223. 1725. Ficus indica maxima, folio oblongo, .. (lámina,!.).

F. glaucescens (Liebm.) Miq., Ann. Mus. Bot. Lugduno-Batavum 3:300. 1868.

Phamnacosycea glaucescens Liebm., Kongel. Danske Vidensk. Selsk. Skr., ser. 5, Naturvidensk. Math. Afh. 2:332. 1851. Lectotipo: México, Veracruz, Mecapalco in Sylvis, 6/41, Liebmann 14314 (C, microficha IDC 2204.146(II.6)!; isolectotipo: C, microficha IDC 2204.146(II.7)!); sintipo: México, Veracruz, Potrero de Consoquitla prope Mirador, 9/41, Liebmann 14315 (C, microficha IDC 2204.146(III.1)!.).

F. hernandezii (Liebm.) Miq., Ann. Mus. Bot. Lugduno- Batavum 3:300. 1868.

Phamnacosycea hemandezii Liebm., Kongel. Danske Vidensk. Selsk. Skr., ser. 5, Naturvidensk. Math. Afh. 2:332. 1851. Tipo: Me'xico, Veracruz, Papantla in Sylvis, 6/41, Liebmann 14316 (Holotipo: C, microficha IDC 2204.146(III.2)!; isotipos C, microficha IDC 2204.146(III.3 y III.4)!).

F. mexicana (Miq.) Miq., Ann. Mus. Bot. Lugduno-Batavum 3:299. 1868.

Pharnacosycea mexicana Miq., Verslagen Meded. Afd. Natuurk. Kon. Akad. Wetensch. 13:415. 1862. Tipo: México, Veracruz, ? Hacienda del Laguna, Schiede 43 (Holotipo: U; isotipo: B, fide de Wolf 1965, 1967, no vistos).

F. pseıdoradula (Miq.) Miq., Ann. Mus. Bot. Lugduno- Batavum 3:299. 1868.

Phamacosycea pseudoradula Miq., Verslagen Meded. Afd. Natuurk. Kon. Akad. Wetensch. 13:414. 1862. Tipo: México, Veracruz, Papantla, Schiede [según la descripción original]. (Holotipo: U, fide de Wolf 1965, 1967, no visto).

F. radula Humb. \& Bonpl. ex Willd., Sp. Pl. 4:1144. 1806. Tipo: Venezuela, in sylvis Orinoci, Humboldt \& Bonpland (Holotipo: B, microficha IDC 7440.1399(I.7)!); isotipo: P, microficha IDC 6029.31(III.5)!).

Nombre común. Acalpu, Amate, Amate de caballo, Gualula, Higo, Higuera, Higuera durazno, Higuera Prieta, Saivo.

Arboles de 5-15(-25) m; contrafuertes 4-8, 0.3-1(-2) m de alto, rectos, raramente sigmoides; fuste 3-5 m de alto, rollizo a ligeramente acostillado, recto, (20-)40-60 cm de 
diámetro arriba de los contrafuertes; corteza café grisácea o verde grisácea, lenticelas inconspicuas, de $1 \mathrm{~mm}$ de diámetro, negras, grises o de color café; exudado café pálido, escaso en la corteza pero abundante en madera y ramas jóvenes, diluido; copa abierta a ligeramente densa, redondeada. Yema terminal 7-20(-56) x (1-)2- $3.2 \mathrm{~mm}$; entrenudos (5-)10-35(-55) x 1.4-5 mm, ovalados, de color café, con la superficie exfoliante en piezas minúsculas irregulares, rugosos, más evidentes donde aun persistenten las hojas, lisos en donde han caído, las cuales se entremezclan con pelos escabrosos, en ocasiones escasos, sin lenticelas evidentes. Hojas (4-)9-19(-22) x (2.7-)5.5-10.5 cm, (1.2-)1.4-2.6(-3) veces más larga que ancha, elípticas u obovadas, raramente ovadas, coriáceas, base cuneada, atenuada u obtusa, ápice agudo o redondeado, anchamente corto apiculado, haz verde grisáceo o verdoso, glabro, a veces escabroso al tacto, envés verde amarillo, escabroso al tacto, pubescente, raramente glabrescente, con tricomas de 0.5-0.8 mm de largo, venas laterales (5-) 7-12 pares, alternas a opuestas, café verdosas o verde amarillas, con escasos pelos estrigosos, el primer par divergente menos de $45^{\circ}$ con respecto a la costa, el resto de $50-80^{\circ}$, las centrales (pares tercero a sexto) 8-22(-33) mm separadas entre sí, más prominentes por el envés; pecíolo (7-)12-36 x 0.9-2.1 mm, aplanado por el haz en fresco y acanalado por el haz al secarse, esta última forma en ocasiones difícil de observar, café obscuro a pálido, superficie exfoliante en minuscúlas piezas irregulares, rugoso, pubescente, glabrescente, con escasos tricomas dispersos entre sí; estípulas 10-21(-40) x 2.5-5 mm, pubescentes. Sicono (0.9- )1.2-2.6(-3) x (0.9-)1.2-2.6 cm, 2-3 x 2-3 cm cuando maduro, esférico, raramente obpiriforme, verde a verde amarillo al madurar, raramente con puntos circulares negros, escabroso al tacto, pubescencia grisa'cea a excepción de las manchas circulares que son glabras, los tricomas cuando presentes, mayores de $0.1 \mathrm{~mm}$ de largo, paredes de 1-2 mm de grosor, osti'olo 1-3 x 2-4 $\mathrm{mm}$, rojizo, aplanado, raramente tubular, menor de $1 \times 1 \mathrm{~mm}$; flores de ca. 772-1332 por sicono, estaminadas ca. 104-228 (13.5-17.1\%) y pistiladas ca. 668-1104 (82.9-86.5\%), estas últimas produciendo ca. 184-244 (13.8-31.6\%) flores "agalladas", ca. 340-552 (41.544\%) abortivas y ca. 84-368 (10.9-27.6\%) semillas; brácteas interflorales (0.5-)1-5 x 0.1-0.5 mm, líneares, lanceoladas o estrechamente elípticas, conduplicadas, rosa pálidas, blancas hacia su base, translúcidas, ápice agudo o redondeado; flores pistiladas con pedicelo de 0-5 x 0-1 mm, terete a aplanado, rosado, sépalos 4(-5), 1-5 x 0.2-0.5(-1) mm, lanceolados o estrechamente oblongos a ovados, conduplicados, algunas veces falcados, rosados, pistilo 1.3-5 mm de largo, ovario 0.8-1.5 x 0.5-0.8 $\times 0.5-0.6 \mathrm{~mm}$, estilo 0.7-4.2 mm de largo; flores estaminadas con pedicelo de $2-5 \times 0.7-1 \mathrm{~mm}$, terete a aplanado, rosado, cáliz rosado, tubo 1-1.5 x 1-1.5 mm, lóbulos 4-5, 1-2 x 0.8-1.2 mm, elípticos, raramente deltados, estambres 2, filamentos $2-3 \times 0.5 \mathrm{~mm}$, aplanados, anteras $1.5-2 \times 1-1.5 \times 0.8-1$ $\mathrm{mm}$, pistilodio $0.4-0.8 \mathrm{~mm}$; frutos 2-2.8 $\times 0.9-1.5 \times 0.6-1 \mathrm{~mm}$, cotiledones $1 \times 0.8 \times 0.2 \mathrm{~mm}$, radícula $0.5 \times 0.2 \mathrm{~mm}$. Pedúnculo del sicono (1-)2-13 x 1.5-2 mm, rollizo, ovalado, verde grisáceo o con tonos de color café o negros, liso a ligeramente estriado, pubescente; brácteas basales 3, 1-1.5 x 2-3 mm, deltoides, ápice agudo, verdes o negras, glabras, prontamente caducas. (fig. 4).

Tipos de vegetación y altitud. Selva alta perennifolia, selvas mediana subperennifolia o subcaducifolia, vegetación secundaria derivada de estos tipos de vegetación, 
riparia, sabana, pastizales o ruderal. Especie raramente observada en vegetación madura; 20-500 (-1200) m snm.

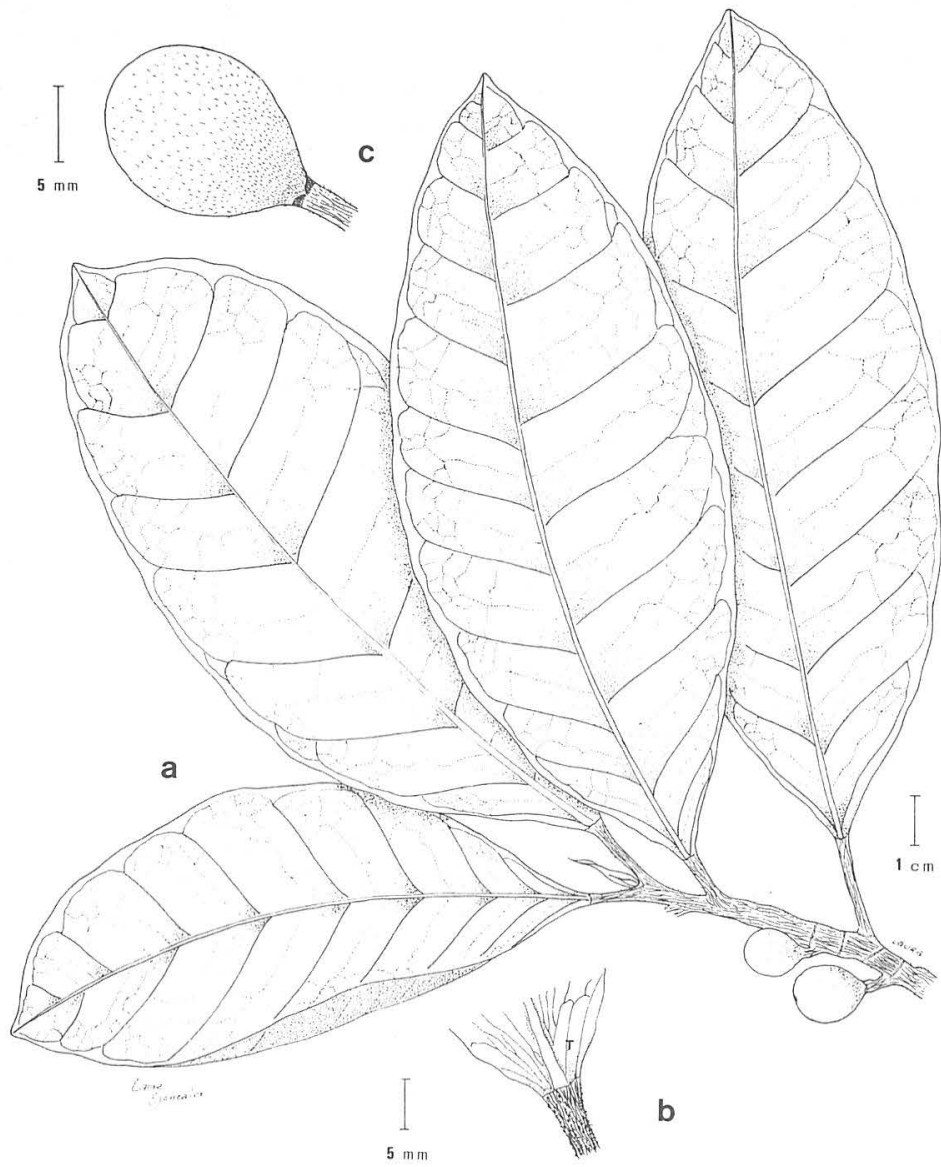

Fig.4. Ficus maxima Mill. A) Rama con hojas y siconos (Calzadla 864), B) detalle del pecíolo de la hoja (Calzada 864), C) detalle del sicono (Calzada 864).

Fenología. Floración y fructificación durante todo el año. Wiebes (1986) menciona que es polinizada por Tetrapus americanus Mayr (Agaonidae), en Brasil y Venezuela.

Distribución geográfica. México (en la vertiente del Pacífico de Sonora a Chiapas, por el Golfo en Veracruz y Tabasco y en toda la Península de Yucatán) hasta Brasil y Paraguay; la distribución en Veracruz se ilustra en la figura 2A. 
Usos. Sombra y alimento (sicono) para ganado en pastizales. El exudado es usado como purgante.

Ejemplares examinados. Mun. Axocuapan, Robles 216 (XAL), Rosas 159 (ENCB, LL, MEXU, US), Sahamer 9475 (MEXU); Mun. Catemaco, Andrle 36 (US), Calzada 414 (CHAPA, F, LL, MEXU), 864 (ENCB, F, MEXU, XAL), Cedillo 3272 (MEXU), Chavelas y Zamora ES- 4887 (MEXU), Ibarra et al. 3257, Martínez 64 (MEXU), Ponce 142 (CHAPA, F, MEXU, XAL), Purpus 14000 (F); Mun. Coatepec, Castillo y Tapia 625 (ENCB, F, MEXU, XAL); Mun. Coatzacoalcos, Calzada 6089 (F, XAL); Mun. Córdoba, Bourgeau 2249 (US); Mun. Juchique de Ferrer, Ibarra et al. 3240; Mun. Misantla, Calzada 4109 (XAL), 4721 (F, XAL), Martínez-M. s.n. (ENCB), Mendoza y Evangelista 81 (MEXU), Miranda 4828 (MEXU); Mun. Nautla, Gómez-Pompa y Riba 21 (MEXU), Gonzólez 66 (MEXU), Ventura 3616 (ENCB, MEXU); Mun. Ozuluama, Avendaño et al. 672 (XAL); Mun. Paso de Ovejas, Vargas 475 (XAL); Mun. San Andrés Tuxtla, Calzada 1530 (MEXU, XAL), Cedillo 392 (MEXU, XAL), Cedillo 2789 (LT, MEXU), 3246 (MEXU), Ibarra y Sinaca 3144, 100 m, Ibarra et al. 3302, 3322; Mun. Tepetzintla, Castillo y Benavides 2332 (XAL), Tapia y Vázquez 133 (XAL); Mun. Tequila, Vázquez-T. 363 (F, MEXU, XAL), Velázquez 127 (F, MEXU, XAL); Mun. Tlapacayan, Ventura 725 (ENCB); Mun. Yecuatla, Ilbarra y Sinaca 3212; Mun. Zongolica, Vázquez-T. 193 (MEXU, XAL), 297 (F, MEXU); Mun. Desconocido, Zacuapan (Zacualpan?), Purpus 7714, 7715 (US).

Comentarios taxonómicos. En este trabajo se incluye bajo este taxón un complejo taxonómico entre Ficus glaucescens y F. maxima. Standley (1917) las consideró como dos especies distintas, aunque indudablemente relacionadas, con base en el grado de pubescencia en el envés de la hoja y el sicono, aunque De Wolf $(1960,1965,1967)$ y Burger (1977) sólo reconocen a $F$. maxima. Nuestra revisión de herbario permite detectar dos aparentes extremos, similares a los sugeridos por Standley: 1) plantas con siconos y envés de la hoja densamente pubescentes, generalmente presentes en tipos de vegetación secos o en altitudes mayores de $1000 \mathrm{~m}$, provenientes de Veracruz y otras localidades de México y Centroamérica ( $F$. glaucescens), y 2) plantas con siconos puberulentos o glabrescentes, con el envés de la hoja glabro o con tricomas escasos, frecuentemente asociadas a tipos de vegetación cálido-húmedos de tierras bajas, localizadas desde México hasta Sudamérica (F. maxima sensu stricto).

Con objeto de establecer si lo anterior permite definir la existencia de dos entidades distintas, se realizaron análisis comparativos con el material depositado en MEXU. Para cada ejemplar del complejo se apuntó el origen geográfico [a) Veracruz, b) otras localidades de México, excluyendo Veracruz y c) Centro-Sudamérica], la altitud y tipo de vegetación cuando se precisaban y los siguientes datos, tomando el promedio obtenido para diez campos distintos: 1) la densidad y longitud de los tricomas en la lámina del envés de la hoja y 2) la densidad y longitud de los tricomas en el sicono.

La figura 5 muestra en forma gráfica la correlación positiva de los caracteres analizados. Las gráficas no proporcionan evidencias robustas de la existencia de dos taxa distintos, puesto que exhiben patrones de variación más o menos continuos, aunque en algunos casos existen concentraciones de individuos cerca de los extremos. En la figura 6 se presenta con más detalle la información para.los ejemplares veracruzanos (fig. 6A) 
y para los ejemplares de todo México, incluyendo Veracruz (fig. 6B), para una sola correlación representativa: longitud de tricomas en la hoja vs. longitud de tricomas en el sicono. Nuevamente, no hay evidencias de dos entidades distintas en cualquiera de las gráficas, aunque es posible observar otra vez la agregación de ciertos individuos. Es notable en Veracruz la escasa representación de plantas con tricomas cortos o ausentes, tanto en la hoja como en el sicono, en comparación con otras partes de México; dichos individuos son los más "típicos" de F. maxima sensu stricto. También se destaca el hecho de que todas las muestras de tierra alta y/o de vegetacio'n relativamente seca, presentan tricomas largos en la hoja y en el sicono, mientras que las provenientes de selvas cálido-húmedas son las más variables al respecto.

Si bien es cierto que lo anterior representa un estudio superficial del problema, los resultados aportan evidencias de que el complejo $F$. maxima-F. glaucescens representa una sola especie, muy variable o, cuando más, dos taxa con intergradación a nivel de dos subespecies o variedades. En este sentido, se sugiere un estudio posterior en toda su área de distribución, que incluya datos sobre sus polinizadores.

${ }^{7}$.n Veracruz, la especie no tiene problemas para su reconocimiento, pues se distingue por el pecíolo con epidermis exfoliante en piezas diminutas, el envés escabroso de sus hojas y siconos rosados o rojizos en su interior cuando frescos. Por el contrario, existen problemas de este taxón para ciertas poblaciones localizadas en Centroamérica (véase esta misma sección para F. insipida).

Ficus petenensis Lundell, Wrightia 3:167.1966. Tipo: Guatemala, Petén, Dolores, in high forest on Río Mopan trail, about $2 \mathrm{~km}, 750 \mathrm{~m}$ SE of village, $\mathbb{E}$. Contreras 2521 (Holotipo: LL!; isotipo: LL!).

Nombre común. Amate, Amate blanco, Amatillo, Amatillo lechero.

Arboles (6-)20-35 m; contrafuertes (0-)3-6, 0.5-3.5 m de alto, rectos; fuste 2-10 m de alto, rollizo a ligeramente acostillado, recto, $0.2-1 \mathrm{~m}$ de diámetro arriba de los contrafuertes, frecuentemente con ramillas cortas reproductivas entre los contrafuertes; corteza café amarilla, verde amarilla o verde grisácea, lenticelas prominentes, de $1 \mathrm{~mm}$ de diámetro, negro verdosas o café grisáceas; exudado blanco, abundante, diluido a ligeramente denso; copa densa, redondeada. Yema terminal 8-19 x 1-2 mm; entrenudos 2.5-18 mm (-45 mm en ramas jóvenes) x 1.3-2.2 mm, ovalados, de color café, glabrescentes, rugosos, sobre todo donde persisten las hojas, a lisos, sin lenticelas evidentes. Hojas (3.5-)5-10(-15) x (0.8-) 2.8-4(-5.2) cm, (2.2-)2.6-4.1(-4.8) veces más largas que anchas, oblanceoladas, elípticas o estrechamente elípticas, raramente obovadas, papiráceas, base atenuada, ápice caudado, acuminado o apiculado, haz verde obscuro, verde amarillo o verde grisáceo, glabro, envés verde pálido o verde amarillento, glabro, venas laterales de (8-)10-18 pares, no visibles en el haz en fresco, verde amarillas, alternas a opuestas, el primer par divergente menos de $45^{\circ}$ con respecto a la costa, el resto de 45-80 , las centrales (par cuarto al octavo) de (3-)5-14 mm separadas entre sí, visibles en ambas caras y menos marcadas por el haz; pecíolo (5-)8-18(-22) x 0.5-1.5 mm, café obscuro, café amarillo o café verdoso, superficie exfoliante en minuscúlas piezas irregulares, rugoso, sulcado por el haz, glabro; estípulas 10-19 x 1-3 mm, glabras. Sicono 0.6-1.7 x 0.6-1.7 cm, 1.1-1.7 x 1.1-1.7 cm cuando maduro, esférico, verde o verde con manchas amarillentas circulares, amarillo al madurar en fresco, verdoso al secar, glabro 
FICUS, SUBGENERO PHARMACOSYCEA EN VERACRUZ
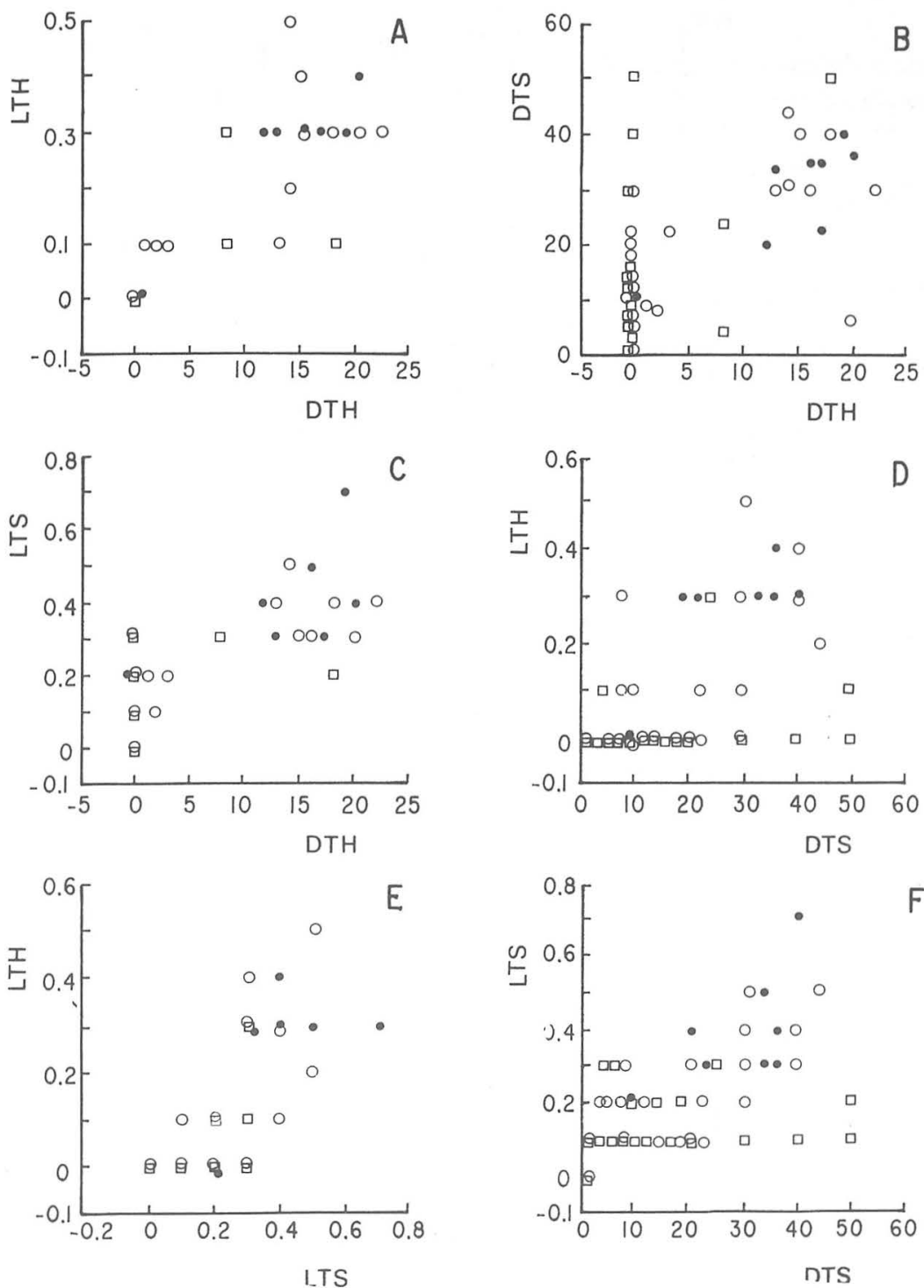

Fig.5. Relaciones entre densidad (número de tricomas por $\mathrm{mm}^{2}$ ) y longitud de tricomas en el envés de la hoja y sicono en Ficus maxima, para tres localidades distintas de América. Abreviaciones. DTH (densidad de los tricomas de la hoja); DTS (densidad de los tricomas del sicono); LTH (longitud de los tricomas de la hoja) y, LTS (longitud de los tricomas del sicono). Simbología. Veracruz (○); México, excepto Veracruz (O) y, Centro-Sudamérica $\square$ 


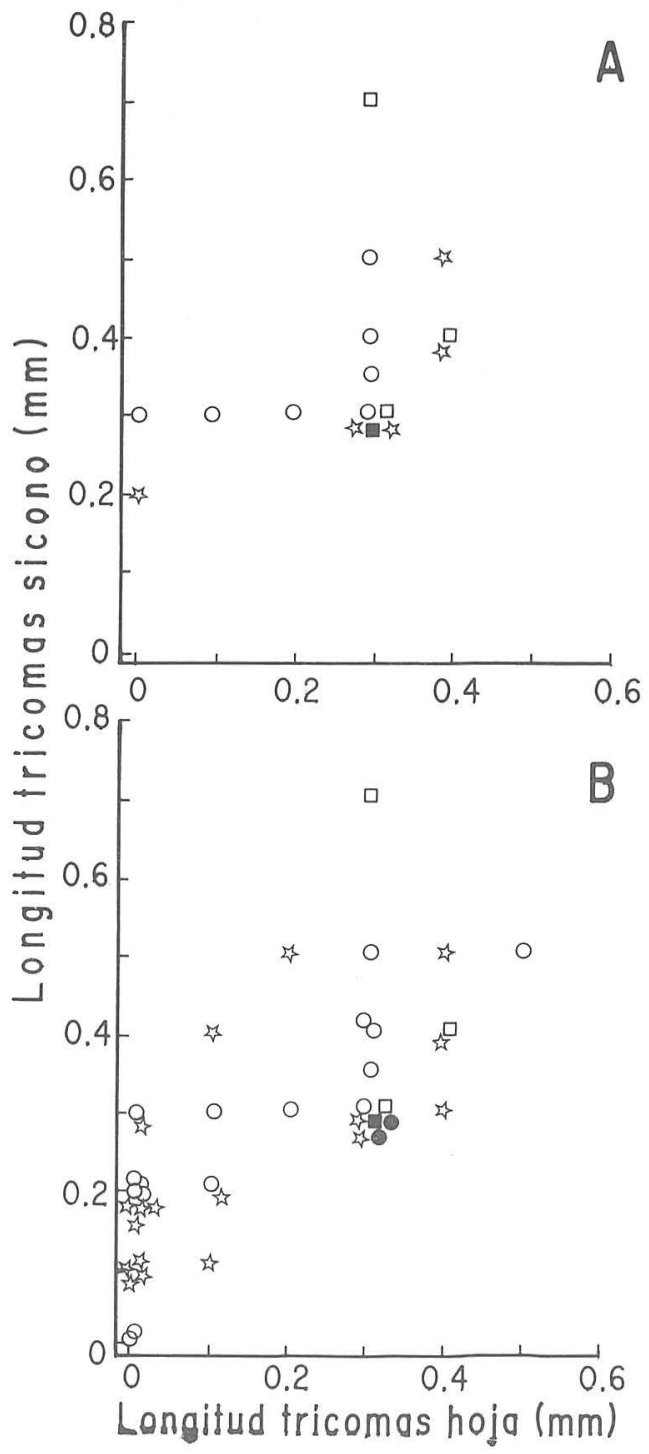

Fig.6. Relaciones entre la longitud de los tricomas del sicono y del envés de la hoja en Ficus maxima, considerando: A) Veracruz, y B) México, incluyendo Veracruz. Simbología. Ejemplares sin datos completos de altitud y tipo de vegetación ( de tierra baja (altitud menor de $1000 \mathrm{~m}$ ) y vegetación húmeda $(\mathrm{O}), 2$ ) de tierra baja y vegetación seca (O), 3) de tierra alta (altitud mayor de 1000 m) y vegetación húmeda ( $\square$ ) y, 4) de tierra alta y vegetación seca (四). 
o finamente puberulento, liso, paredes 1-1.5 mm de grosor, ostíolo aplanado o sobre una columna apical de hasta $0.5 \mathrm{~mm}$ de largo; flores de ca. 588-624 por sicono, estaminadas ca. 80-120 (12.8-20.4\%) y pistiladas ca. 468-544 (83.8-87.2\%), estas últimas produciendo ca. 80-312 (13.6-50.0\%) flores "agalladas", ca. 144- 372 (23.1-63.3\%) abortivas y ca. 16-88 (2.7-14.4\%) frutos; brácteas interflorales 1-3.5 x 0.2-0.5(-1.2) mm, lanceoladas, conduplicadas, blancas, translúcidas, costa evidente, ápice agudo o acuminado; flores pistiladas con pedicelo de (0-)1-3.5 x (0- )0.4-0.8 mm, terete a aplanado, blanco; sépalos 4-5, 1.4-3 x 0.2- 0.5(-0.8) $\mathrm{mm}$, estrechamente oblongos a lanceolados, conduplicados, raramente falcados, blancos, pistilo 1.5-3.5 mm de largo, ovario 0.8-1.1 x 0.6-1 x 0.5-0.6 $\mathrm{mm}$, estilo 0.6-3 mm de largo; flores estaminadas con pedicelo de 1-2.5 x 0.5-0.7 mm, terete a aplanado, blanco, cáliz blanco, tubo 0.5-1 x 0.9-1.2 mm, lóbulos (4-)5, 1-1.6 x 0.5-1 mm, elípticos o estrechamente elípticos, estambres (1-)2, filamentos 1.5-2.5 x 0.3-0.5 mm, aplanados o semiteretes, anteras 1-1.7 x 0.8-1 x 0.4-0.7 mm, pistilodio 0.1-0.5 $\mathrm{mm}$; frutos 1.8-2.3(-2.8) x 1-1.5 x 0.8-1.1 mm, cotiledones $0.7-1 \times 0.5-0.6 \mathrm{~mm}$, radícula 0.3-0.5 x $0.2 \mathrm{~mm}$. Pedúnculo del sicono ausente (presente en siconos observados en Wendt et al. 4065 e Ilbarra 3253, ca. $1 \times 1 \mathrm{~mm}$, rollizo, negro, liso, glabro); brácteas basales 3, 1-1.5 x 1-1.5 mm, deltoides, ápice agudo, verdes, glabras, caducas, difíciles de observar en el material herborizado. (fig. 7).

Tipos de vegetación y altitud. Selva alta perennifolia, selva mediana subperennifolia, vegetación secundaria derivada de estos tipos de vegetación, riparia, pastizales o como ruderal; 50-400(-600) m snm.

Fenología. Floración y fructificación durante todo el año.

Distribución geográfica. México (Puebla, Veracruz, Campeche, Oaxaca y Chiapas) hasta Ecuador y Colombia; la distribución en Veracruz se ilustra en la figura 2B.

Usos. Sombra y alimento (sicono) para ganado en pastizales. La madera se usa para la elaboración de triplay.

Ejemplares examinados. Mun. Coatzacoalcos, León 113 (MEXU), Miranda 3315 (MEXU), Purpus 3784 (F, US), 16255 (F); Mun. Hidalgotitlán, Wendt et al. 2611, 3754, 4065 (CHAPA); Mun. Minatitlán, Wendt et al. 2654 (CHAPA, XAL); Mun. San Andrés Tuxtla, Calzada 332 (F, XAL), 1252 (XAL), Cedillo 167 (CHAPA, ENCB, MEXU, XAL), 2767 (MEXU), 3759 (LT, MEXU), Gentry et al. 32353, 32574, Gómez-Pompa 4487 (MEXU), González y Garza 8459, 8464, 8613 (MEXU), Ibarra 309, 865 (LT), 640 (MEXU, XAL), Ibarra et al. 3083, 3094, 3114, 3138, 3323, 3249, 3250, 3253, 3254, 3255, 3455 , Ibarra y Sinaca 3339, Ibarra 3304, 3504, Rosas 1748, 1749, 1859 (MEXU), Sinaca et al. 526, 1633 (LT, MEXU), Mun. Desconocido, Purpus s.n. (TEX), Tepezentela, J. y C. Taylor 7381 (US).

Comentarios taxonómicos. Esta especie no ha sido incluida hasta el momento en ningún tratamiento taxonómico para el género o la familia, debido a determinaciones erróneas. En Veracruz presenta características muy constantes que permiten su facil determinación, básicamente por sus pecíolos con la superficie exfoliante en piezas diminutas, lámina no áspera al tacto, con ápice caudado y siconos sésiles, finamente pubescentes, blancos en su interior en fresco. Cabe destacar que la región de "Los Tuxtlas" parece ser la única zona en Veracruz donde se presentan densidades apreciables de este árbol. Lo escaso de sus colectas, incluso para localidades fuera de México, 


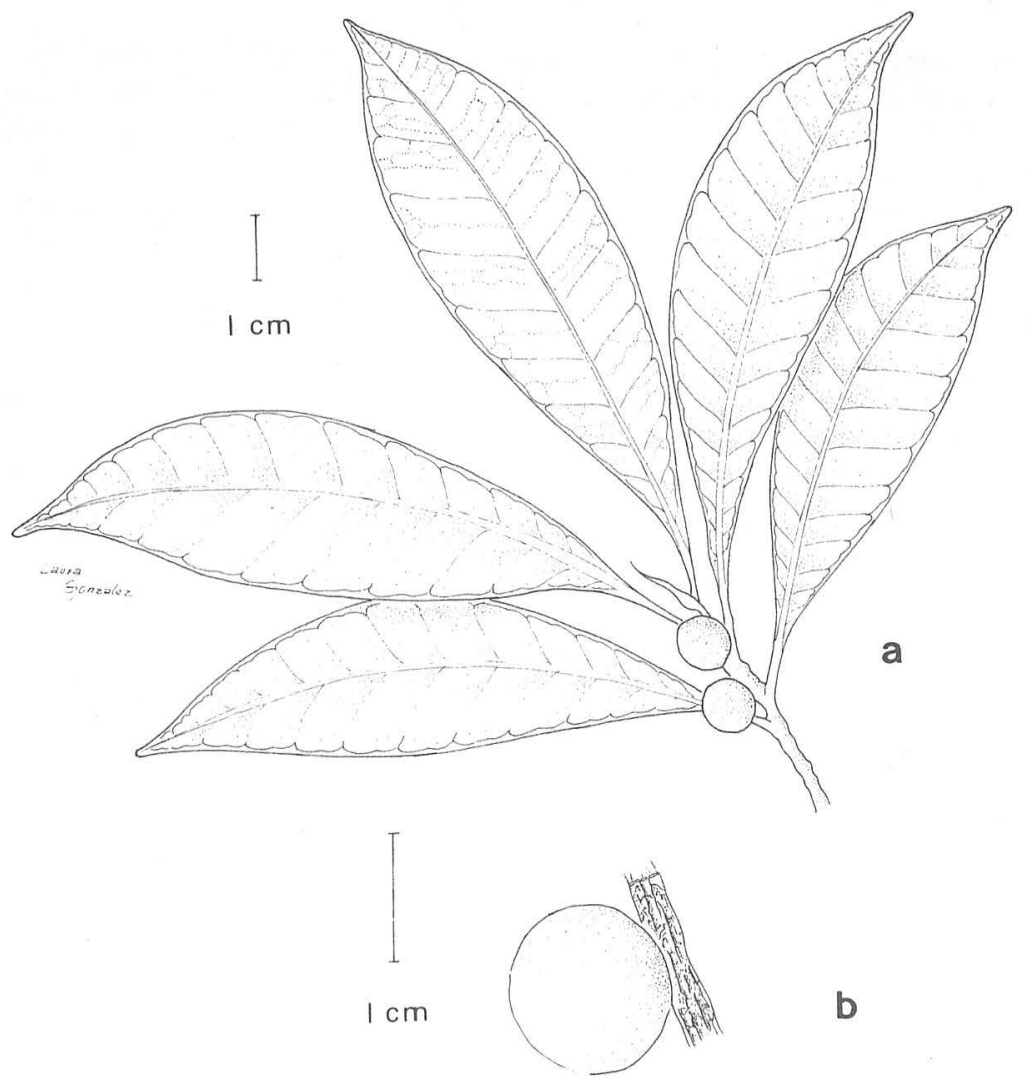

Fig.7. Ficus petenensis Lundell. A) Rama con hojas y siconos (Ibarra 3323), B) detalle de la rama y sicono (Ibarra 3323).

sugiere poblaciones reducidas en los sitios donde habita, situación que de confirmarse posteriormente, la ubicará como una especie en peligro de extinción.

Ficus yoponensis Desv., Ann. Sci. Nat. Bot. Ser. 2, 18:310. T. 8,

fig. 1. 1842. Tipo: Venezuela, Río Yopo, Hamilton s.n. (Tipo: P, fide De Wolf, 1965, no visto). [La descripción original incluye una lámina muy detallada].

Nombre común. Amate, Amate caballo, Higuera, Higuera blanca.

Arboles de 10-30(-40) m; contrafuertes 3-6, 0.5-3 $\mathrm{m}$ de alto, rectos; fuste 4-15 $\mathrm{m}$ de alto, rollizo a ligeramente acostillado, recto, 0.3-1.5 m de diámetro arriba de los contrafuertes; corteza café grisácea o café verdosa, lenticelas inconspicuas, de $1 \mathrm{~mm}$ de diámetro, de color café o negras; exudado blanco, abundante, denso, urticante al contacto con la piel; copa densa, redondeada. Yema terminal 22-50(-75) x 1.5-2.5 mm; entrenudos 5-21 mm (-33 en individuos juveniles) x 1.5-4.5 mm, ovalados a ligeramente sulcados, café amarillos, glabros, lenticelas abundantes, distribuidas irregularmente o 
no evidentes. Hojas (4-)8-19 cm (- $36 \mathrm{~cm}$ en individuos juveniles) x (2-) $3.5-7.2 \mathrm{~cm}$, 1.8-3.6(-5.5 en individuos juveniles) veces más larga que anchas, oblanceoladas, elípticas o estrechamente elípticas, raramente obovadas, papiráceas, base aguda o cuneada, ápice acuminado o cortamente apiculado, haz verde obscuro o verde grisáceo, glabro, envés verde pálido o verde amarillento, glabro, vena submarginal visible, con los arcos de las venas secundarias menores de 1(- 1.5) mm de largo, venas laterales de (13-)16-22(-27) pares, verde amarillas, alternas a opuestas, el primer par y en ocasiones también el segundo par, divergente menos de $45^{\circ}$ con respecto a la costa, el resto de $45-80^{\circ}$, las centrales (par séptimo al décimo segundo) de 3.5-10 mm separadas entre sí, visibles en ambas caras y menos marcadas por el haz; pecíolo (5-)15-27(-42) x 0.5-2 mm, verdoso a café pálido, liso, ligeramente sulcado por el haz en fresco, acanalado por el haz al secar, glabro; estípulas 25-50(-75) x 2.5-4(-5) mm, glabras. Sicono 0.6-2 x 0.6-2 cm, 1.3-2 x 1.3-2 $\mathrm{cm}$ cuando maduro, esférico, verde con manchas amarillentas circulares, amarillo al madurar en fresco, verdoso, café o negruzco al secar, glabro, liso, paredes 1-2 mm de grosor, ostíolo sobre un tubo apical, 1-3 x 1-1.5 mm, prominente, con brácteas menores de $1 \times 1 \mathrm{~mm}$, verdes; flores de ca. 780-864 por sicono, estaminadas ca. 100-140 (12.8$16.2 \%)$ y pistiladas ca. 680-724 (83.8-87.2\%), estas últimas produciendo ca: 304-324 (35.2-41.6\%) flores "agalladas", ca. 276-288 (31.9-36.9\%) abortivas y ca. 68-144 (8.7$16.7 \%$ ) frutos; brácteas interflorales (0.5-)1.8-4 x 0.1-0.8 mm, líneares, lanceoladas o estrechamente elípticas, conduplicadas, blancas, translúcidas, ápice agudo; flores pistiladas con pedicelo de (0-)1-3.2 x (0-)0.4-1 mm, terete a aplanado, blanco, sépalos 4-5, (0.8-)1.8-3 x 0.2-0.5 mm, lanceolados, conduplicados, algunas veces falcados, blancos, pistilo 1.2-3.6 mm de largo, ovario 0.9-1.1 x 0.5-0.7 x 0.4-0.5 mm, estilo 0.5-3 mm de largo; flores estaminadas con pedicelo de 2-3.5 x 0.4-0.6 mm, terete a aplanado, blanco, cáliz blanco, tubo (0.5-)0.8-1 x 0.6-1.2 mm, lóbulos 4(-5), (0.5-)1-1.5 x 0.4-1 mm, elípticos o estrechamente elípticos, raramente deltoides, estambres 2, filamentos 1.2- $1.8 \times 0.3-0.5$ $\mathrm{mm}$, aplanado o semiteretes, anteras 1-1.5 $\times 0.5-0.8 \times 0.5-0.6 \mathrm{~mm}$, pistilodio $0.2-0.3 \mathrm{~mm}$; frutos 1.7-2.5 x 1-1.5 x 0.8-1 mm, cotiledones $1 \times 0.5 \times 0.5 \mathrm{~mm}$, radícula $0.4 \times 0.2 \mathrm{~mm}$. Pedínculo del sicono 6-11(- 13.5) x (0.6-)1-2 mm, rollizo, raramente más grueso hacia ambos extremos, café o negro, liso, glabro; brácteas basales $3,0.6-2 \times 1.5-4 \mathrm{~mm}$, raramente alguna desplazada hasta la parte media del sicono, deltoides, ápice agudo a redondeado, verdes en fresco, verdes o negras al secar, glabras, prontamente caducas. (fig. 8).

Tipos de vegetación y altitud. Selva alta perennifolia, vegetación secundaria derivada de ésta, riparia, pastizales o como ruderal; 50-600 m snm.

Fenología. Floración y fructificación durante todo el año. Wiebes (1986) menciona que es polinizada por Tetrapus ecuadoranıs Grandi (Agaonidae) en Panamá.

Distribución geográfica. México (Veracruz y Chiapas) hasta Panamá y Venezuela; la distribución en Veracruz se ilustra en la figura 2B.

Usos. Sombra y alimento (sicono) para ganado en pastizales. La madera se usa para la elaboración de triplay. El exudado es útil como purgante.

Ejemplares examinados. Mun. Atzalán, Ibarra y Sinaca 3229; Mun. Catemaco, Castillo y Dorantes 2635 (XAL), Cedillo 2910 (MEXU), González y Garza 6370, 6744, 8386 (MEXU), Nee y Calzada 22536 (F, XAL); Mun. Juchique de Ferrer, Ibarra et al. 


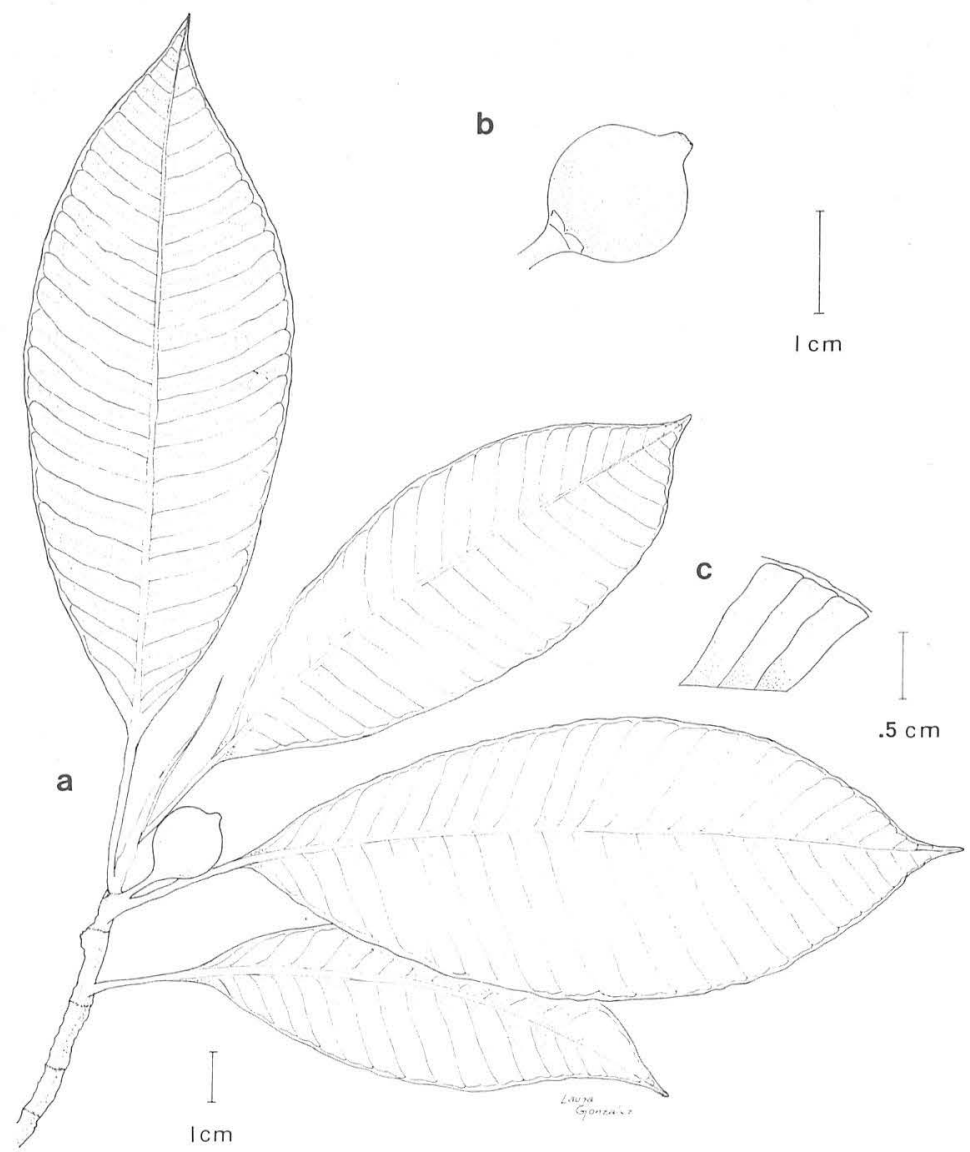

Fig.8. Ficus yoponensis Desv. A) Rama con hojas y siconos (Ibarra 1837) detalle del sicono (Ibarra 1837).

3221,3222,3237, 3238,3239; Mun. Misantla, Gómez-Pompa 918 (MEXU), Martínez-M. s.m. (ENCB); Mun. San Andrés Tuxtla, Cedillo 2862, 3228, 3773 (MEXU), Flores 38 (MEXU), Horvitz et al. 124 (MEXU), Ilbarra 574 (LT, XAL), 758 (LT), Ibarra y Sinaca 1837 (LT, MEXU), 1928 (LT, MEXU, XAL), Ibarra et al. 2501 (LT, MEXU), 3251, 3252, 3283, 3285, Ibarra 3299, 3321, 3360, 3555; Torres y Hernández 3293 (MEXU), Ramamoorthy e Ilbarra 3569 (MEXU); Mun. Santiago Tuxtla, Ilbarra y González 3248; Mun. Soteapan, Acosta et al. 1365 (TEX).

Comentarios taxonómicos. Este taxón es determinado frecuentemente como $F$. insipida Willd., pero existen claras diferencias morfológicas y ecológicas que permiten su separación en Veracruz (ver esta misma sección para aquella especie). Cuando las 
plantas carecen de siconos, se hace más compleja su determinación, aunque tenemos la convición de que se trata de dos entidades distintas, pues no tenemos ninguna evidencia de que se encuentren individuos de caracter intermedio entre ellas, incluso en localidades donde comparten el mismo habitat (p. ej. la región de Los Tuxtlas). Ficus yoponensis se distingue básicamente por sus hojas generalmente más anchas de su parte media hacia el ápice, vena submarginal presente, generalmente con los arcos de las venas secundarias menores de $1 \mathrm{~mm}$ de largo y siconos más pequeños y blancos en su interior cuando frescos.

AgRAdECIMIENTOS. Quisiéramos hacer un reconocimiento especial a Santiago Sinaca Colín, Laura González García y Miguel Angel Sinaca Colín, por su invaluable ayuda en el trabajo de campo. A Laura y a Felipe Villegas, la elaboración de las ilustraciones incluidas en el trabajo. A Fernando Chiang, María de Lourdes Rico Arce, Nidia Pérez Nasser y un revisor anónimo, sus atinadas sugerencias para mejorar el contenido del artículo; a Carol Todzia por su información sobre las especies de Ficus presentes en Nicaragua y a Armando Butanda su ayuda para resolver muchos de los problemas inherentes con la publicación. Damos las gracias a los curadores de los herbarios CHAPA, ENCB, F, LL, MEXU, TEX US y XAL, por permitirnos consultar el material de Ficus. El autor principal agradece a CONACyT el goce de una beca de postgrado durante 1988 y al Dr. Antonio Lot Ilelgueras el apoyo recibido para la realización de los estudios de maestría. El trabajo de campo fue apoyado por CONACyT, a través del proyecto Flora Mesoaméricana (Colegio de Postgraduados) y por el Centro de Botánica del Colegio de Postgraduados de Chapingo.

\section{LITERATURA CITADA}

BERG, C.C. 1973. Some remarks on the classification and differentiation of Moraceae. Meded. Bot. Mus. Herb. Utrecht 386:1-10.

BERG, C.C. y J.E. SiMONIS. 1981. The Ficus flora of Venezuela: five species complexes discussed and two new species described. Ernstia 6:1-10.

BERG, C.C. 1983. Dispersal and distribution in the Urticales - an outline-. Sonderbd. naturwiss Ver. Hamburg 7:219-229.

BERG, C.C., M.A. VÁZQUEZy F. KOOY. 1984. Ficus species of Brazilian Amazonia and The Guianas. Supl. Acta Amazonica 14(1/2):159-194.

BERG, C.C. 1989. Classification and distribution of Ficus. Experientia 45:605-611.

BERG, C.C. 1990. Reproduction and evolution in Ficus (Moraceae): traits connected with the adequate rearing of pollinators. Mem. N.Y. Bot. Gard. 55:169-185.

BURGER, W.C. 1973. Notes on the flora of Costa Rica 3: new species in Moraceae. Phytologia 26(6):421434.

BurGER, W. C. 1977. Moraceae. En: Burger, W. (Edr.). Flora Costaricensis. Fieldiana Bot. 40:94-215.

CARAUTA, P.J.P. 1989. Ficus (Moraceae) no Brasil: conservacao e taxonomia. Albertoa 2:1-365.

CONDIT, I. J. 1969. Ficus: the exotic species. Universiity of California, Berkeley, 363p.

CORNER, E.J.H. 1962. The classification of Moraceae. Gard. Bull. Singapore 19(1):187-252.

CORNER, E.J.H. 1965. Check-list of Ficus in Asia and Australasia with keys to identification. Gard. Bull. Singapore 21:1-186. 
CORNER, E.J.H. 1985. Essays on Ficus. Allertonia 4(2):125-154.

CORNER, E.J.H. 1985a. Ficus (Moraceae) and Hymenoptera (Chalcidoidea): figs and their pollinators. Biol. J. Linn. Soc. 25:187-195.

CROAT, T.B. 1978. Flora of Barro Colorado Island. Stanford University Press, Stanford. pp.350-357.

DE WOLF, G.P. Jr. 1960. Ficus (Tourn.) L. En: Woodson, R.E. Jr. y R.W. Schery (Edrs.). Flora of Panama (Moraceae). Ann. Missouri Bot. Gard. 47(4):146-165.

DE WOLF, G.P. Jr. 1965. Ficus, subgenus Pharnacosycea in America. Elliottia 4:1-20.

DE WOLF, G.P. Jr. 1967. Ficus subg. Pharmacosycea sect. Pharmacosycea. Hookers's Icon. P1. 37: t. 3634-3636.

GALIL, J. y D.E. EISIKOWITCH. 1968. On the pollination ecology of Ficus sycomorus in east Africa. Ecology 49(2):259-269.

GÓMEZ-POMPA, A. 1966. Estuđios botánicos en la región de Misantla, Veracruz. Instituto Mexicano de Recursos Naturales Renovables, A. C., México. (pp:135-140).

GómeZ-PompA, A. y NEvLInG, L.I. Jr. 1970. La flora de Veracruz. An. Inst. Biol. Univ. Nac. Autón. México, Ser. Bot. 41(1):1-2.

HAMMEL, B. E. 1986. The vascular flora of La Selva Biological Station, Costa Rica. Selbyana 9:243-259.

HEMSLEY, B. W. 1883. Urticaceae. En: Godman, F.D. y O. Salvin. Biologia Centrali-Americana; or Contributions to the knowledge on the fauna and flora of Mexico and Central America. R.H. Porter, London. pp.14-152.

HILL, D.S. 1967. Figs (Ficus spp.) of Hong Kong. Hong Kong University Press, Hong Kong, 130p.

IBARRA-MANRÍQUEZ, G. 1990. Taxonomía del género Ficus, subgénero Pharmacosycea (Moraceae) en Veracruz, México. Tesis Maestría, Colegio de Postgraduados, Chapingo,. México, 96p.

IBARRA-MANRÍQUEZ, G. 1991. Ficus (Moraceae): un género interesante para estudios en ecología y sistemática tropical. Ciencia (México) 42:283-293.

IBARRA-MANRÍQUEZ, G. 1992. Las plántulas de Ficus subgénero Pharmacosycea (Moraceae) en Veracruz, México. Acta Bot. Mex. 18:55-69.

JANZEN, D. H. 1979. How to be a fig. Ann. Rev. Ecol. Syst. 10:13-51.

LIEBMANN, F. 1851. Mexicos og Central-Americas neldeagtige planter (Ordo: Urticaceae) indbefattende familierne: Urticeae, Moreae, Artocarpae og Ulmaceae. Kjo"benhavn (trykt hos Kgl. Hofbogtrykker Bianco Luno). reprinted from K. danske Vid. Selsk. Skr. ser. 5, naturv. math. Afd. 2:285-343.

RAMÍREZ, W.B. 1969. Fig wasp: mechanism of pollen transfer. Science 163:580-581.

RAMíREZ, W.B. 1970. Host specificity of fig wasp (Agaonidae). Evolution 24:680-691

RAMíreZ, W.B. 1974. Coevolution of Ficus and Agaonidac. Ann. Missouri Bot. Gard. 61:770-780.

RAMíreZ, W.B. 1977. A new classification of Ficus. Ann. Missouri Bot. Gard. 64:296-310.

RAMÍREZ, W.B. 1986. fatificial hybridization and self-fertilization in Ficus (Moraceae). Brenesia 25 26:265-272.

RAMíREZ, W.B. 1989. Dispersal and colonization of Ficus in the New World. En: Crane, P.R. y S. Blackmore (Edrs.). Evolution, systematics, and fossil history of the Hamamelidae. v. 2 'Higher' Hamamelidae. Systematics Association Special Volume No. 40 B. Clarendon Press, Oxford. pp.279-284.

StANDLEY, P.C. 1917. The Mexican and Central American species of Ficus. Contr. U. S. Natl. Herb. 20(1):1-35.

STANDLEY, P.C. 1922. Trees and shrubs of Mexico. Contr. U. S. Nat1. Herb. 23(2):171-516.

StANDLEY, P.C. 1937. Flora of Costa Rica. Part II. Field Mus. Nat. Hist. Bot. Ser. 18:384-388.

STANDLEY, P.C. y J.A. STEYERMARK. 1946. Flora of Guatemala. Fieldiana Bot. 4(4):30-48.

VÁZQUEZ-ÁVILA, M. 1981. El género Ficus (Moraceae) en la República Argentina. Darwiniana 23 (2-4): 605-636.

VERKERKE, W. 1989. Structure and function of the fig. Experientia 45:612-622.

WIEBES, J.T. 1979. Co-evolution of figs and their insect pollinators. Ann. Rev. Ecol. Syst. 10:1-12. 
FICUS, SUBGENERO PHARMACOSYCEA EN VERACRUZ

WIEBES, J.T. 1982. Fig wasp (Hymenoptera). Monographie Biologicae 2:735-755.

WIEBES, J.T. 1984. Fig wasp-fig co-evolution. Antenna 8(3):122-127.

WIEBES, J.T. 1986. Agaonidae (Hymenoptera, Chalcidoidea) and Ficus (Moraceae):fig wasps and their figs I. Proc. Kon. Ned. Akad. van Wetensch. C89(3):335-355.

WIEBES, J.T. 1986a. The association of figs and figs-insects. Revue Zool. Afr. 100:63-71. 